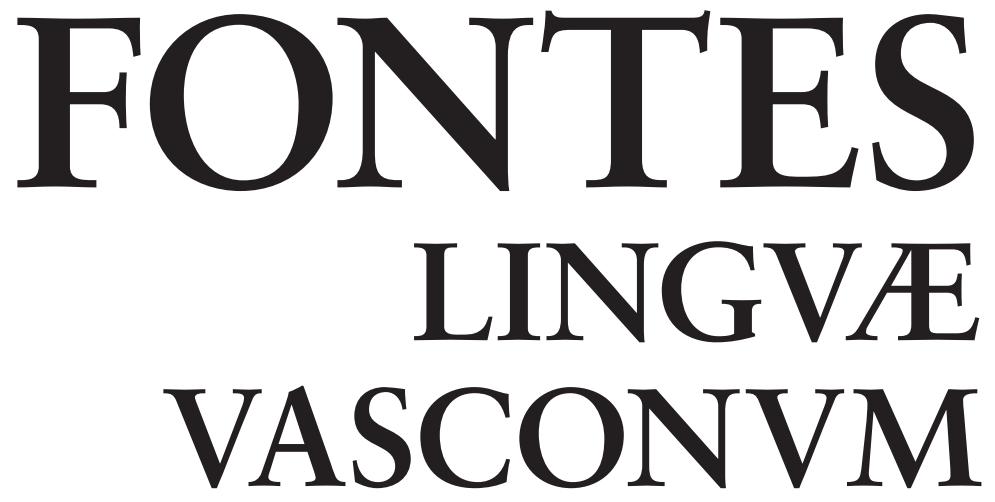

STVDIA ET DOCVMENTA

SEPARATA

Sobre el elemento indoeuropeo pre-latino en la toponimia de Vasconia: los nombres de lugar terminados en -ama

Luis Mari ZalduA

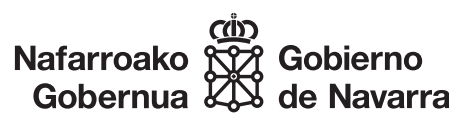

0000 


\section{Sumario / Aurkibidea}

Fontes Lingvæ Vasconvm. Stvdia et Docvmenta

Año XLVIII. urtea - N.o 121. zk. - 2016

Erroibarko aldaeraren inguruan

(2 - Hego Erroibarko azpialdaera. Lehen erdia)

Koldo Artola

Zaraitzueraren lekukotasunak XVIII. mende bukaeran:

hiru testu zahar eta autore berri bat

Ekaitz Santazilia

Dardarkari bakunaren alofonoez testu irakurrietan

Iñaki Gaminde, Asier Romero, Naia Eguskiza eta Aintzane Etxebarria

Nola erabili itzulpena euskarazko irakaskuntza elebi/eleaniztunean

Testuliburu bateko adibideen azterketa eta proposamen didaktiko zenbait

Nere Etxezarraga

La adaptación del Patrimonio Oral Vasco como recurso simbólico de la comunidad vasca (1960-1975)

Ana Gandara

Sobre el elemento indoeuropeo pre-latino en la toponimia de Vasconia:

los nombres de lugar terminados en -ama

Luis Mari Zaldua

Idazlanak aurkezteko arauak / Normas para la presentación de originales 


\title{
Sobre el elemento indoeuropeo pre-latino en la toponimia de Vasconia: los nombres de lugar terminados en -ama
}

\author{
Luis Mari ZALDUA ${ }^{1}$ \\ Doctor en Filología Vasca. luismarizaldua@gmail.com
}

La toponimia podría hacer bastante para aclarar, o al menos para plantear, ciertos problemas históricos, pero tendría que ser una toponimia estudiada con criterios geográficos más que etimológicos.

K. Mitxelena

\section{INTRODUCCIÓN}

De un tiempo a esta parte, con motivo de la publicación de una serie de trabajos por parte del profesor y académico Patxi Salaberri ${ }^{2}$, los estudios sobre la toponimia mayor de Vasconia han experimentado un significativo avance. Sin menoscabo de otros apartados, como, por ejemplo, el de los topónimos descriptivos, reviste especial importancia la aportación realizada por el onomasta de Ujué en el campo de los nombres de lugar de origen deantroponímico.

Salaberri suscribe el interés de Mitxelena por reflejar en un mapa la distribución geográfica de los diferentes sufijos que están presentes en los deantropónimos, pero matiza que, previamente, hay que identificar todos los que existen y, para eso, es necesario dar una explicación etimológica satisfactoria de muchos de ellos.

En una serie de publicaciones que inicia el año 2000 con un artículo acerca del sufijo toponímico -ain y culmina en 2015 con una monografía sobre los nombres de los pueblos de Álava, Salaberri, además de recoger y comentar las opiniones de otros investigadores que se han ocupado de los sufijos de origen latino añadidos a bases

1 El más sincero agradecimiento al profesor Patxi Salaberri por la ayuda prestada para elaborar de este artículo.

2 Vid. $\$ 7$. 
antroponímicas para crear topónimos que indican posesión (Caro Baroja, Mitxelena, Irigoien...), estudia pormenorizadamente multitud de topónimos mayores y menores de Vasconia que los portan y señala la extensión de cada uno de ellos. Se trata de sufijos como -anu, -ano, -ana (eus. -au, -ao, -a), -ain, -ika, -iko (-iku), -(i)(t)z, -inu, -ina, -itu o -ita. El profesor navarro se centra en presentar conclusiones de carácter especialmente lingüístico, aunque es consciente de que, desde muchos puntos de vista, se le podría sacar bastante más provecho a la obra que publica.

En sus libros y artículos, al proponer la etimología de algunos topónimos, Salaberri también se ocupa de otras terminaciones, entre las que se encuentra -ama, que, como bien es sabido, a Mitxelena le recuerda el sufijo indoeuropeo -ama, -isama. En su reciente libro sobre los nombres de los pueblos de Álava Salaberri también le dedica varios párrafos. No es de extrañar que no se extienda mucho, ya que en la toponimia de Vasconia la terminación -ama no es tan abundante como los sufijos de origen latino empleados con bases antroponímicas. Además de tratarse de un corpus ciertamente reducido, conviene recordar, igualmente, que los autores que se han ocupado de -ama coinciden en que seguramente es de origen indoeuropeo (pre-latino).

Ahora bien, habida cuenta del corto número de préstamos indoeuropeos pre-latinos en la lengua vasca y los pocos nombres de lugar de esa procedencia, a pesar de lo exiguo del corpus, el estudio conjunto de los topónimos de Vasconia terminados en -ama puede revestir cierto interés, allende, incluso, la onomástica.

Este trabajo amplía, en primer lugar, el inventario de nombres de lugar terminados en - ama estudiados hasta la fecha con nuevas muestras (Bedama, Enzama, Erama, Leizama, Lizama...). Una vez clasificados, teniendo presente las aportaciones de otros autores, se procura aclarar el posible origen de los topónimos que portan la terminación en cuestión, para, finalmente, analizar su distribución territorial e intentar extraer algunas conclusiones sobre el elemento indoeuropeo pre-latino en la toponimia de Vasconia.

Salaberri subraya que, junto a los sufijos, es importante también tener claro cuáles son los modelos de topónimo que se dan, puesto que de esa manera resulta más fácil (o menos complicada al menos) la explicación de los diferentes nombres. Se toma nota de ello y se procura estudiar series de topónimos, de manera que si un nombre puede ser incluido dentro de un grupo (Araka, Arakama; Amiao [Amiano], Amiama...) su explicación etimológica gana en fiabilidad (<Aracus, Amius...). Obviamente, se utilizan y aprovechan para ello las publicaciones sobre deantroponimia de Salaberri; es más, este trabajo no hubiera sido posible sin la previa existencia de la obra del profesor de Ujué.

Se interioriza también su afirmación de que hay muchos paralelismos entre los sistemas onomásticos vasco y romance. En consecuencia, se comparan, siempre y cuando las fuentes documentales lo permiten, datos de ambos sistemas (Zezama [Álava, A], Cezana [Asturias, AS]; Beizama [Gipuzkoa, GI], Beizana [A Coruña, ACO]).

Queda pendiente para otra ocasión el estudio conjunto de los topónimos de Vasconia terminados en -amo, es decir, con moción de género masculino (Arkamo [monte, A], 
Godamo [paraje, Urkabustaiz, A], Zaratamo [municipio, Bizkaia, BI], Orizamo [caserío, Etxebarri, Bi]...). No obstante, se consideran puntualmente aquellos que pueden ser dobletes de otros con la terminación -ama (Legizamo, Beramo, Lexamona).

Finalmente, se excluyen de este artículo topónimos como Aima (monte, Lagrán, A), Cucuma / Cucumaran / Cucuna (paraje, Araia, A), Herezuma (caserío, Errigoitia, BI) I Errezuma (caserío, Goizueta, Navarra, [NA]), Mioma (pueblo, A), Oma (caserío, barrio, Kortezubi, BI), Osuma (caserío, Deba, Soraluze, GI), Puyancama (labrantío, Orbiso, A), Trama (caserío, Gernika-Lumo, BI), Valdama (monte, Mioma, A), Valderrama (monte, Artziniega, A) o Vaulalama (paraje, Carranza, BI), por no existir de momento, más allá de cierta semejanza formal, razones de peso que apunten a una posible relación con el objeto de estudio de este trabajo, sino, más bien, en la mayoría de casos, claros indicios de lo contrario. Tampoco se contemplan aquellos topónimos que tienen su origen en genéricos eusquéricos conocidos, como Iturrama ('manantial') o Zarama ('broza').

Por lo que se refiere a las fuentes empleadas, se han consultado revistas especializadas, libros (tanto de lingüística como de historia) y, ocasionalmente, algún archivo público. También se han empleado ediciones digitales de documentos históricos, así como bases de datos onomásticos en línea de varios organismos públicos (gobiernos, diputaciones forales, universidades, academias).

\section{ANTECEDENTES}

Mitxelena no es el primero en ocuparse de $-a m a^{3}$. Como él mismo reconoce, tanto Meyer-Lübke (1925: 69-71 [530-532]) como Bähr (1948: 38) señalan ya que la terminación no se deja explicar por el euskera y que las bases a las que acompaña tampoco son vascas. El maestro de Errenteria concreta que los topónimos vascos en -ama son probablemente designaciones indoeuropeas, y en su obra ( $A V, 39$ y 347; 1960: 247-248; 1964 : 133; 1968: 485-486), además de los topónimos Aldama, Arama, Beizama, Berama, Lezama, Ultzama y Zegama, cita el apellido Leguizamón y los pares Aldama / Aldamiz y Lezama / Lezamiz; los compara con los indoeuropeos Letisama, Uxama, Segisama, así como con los romances Ledesma y Osma. Destaca, entre otras cosas, que en los topónimos vascos en -ama (Beizama, Ultzama) nos topemos con $/ z /$, y no $/ s /$.

Albertos (1966: 295), en su tesis sobre la onomástica personal primitiva de Hispania, habla de sufijos con -m-, frecuentes en las lenguas celtas y que muchas veces tenían en su origen un valor superlativo, bien en la forma -mo- o -amo $\left({ }^{*}-m m o-\right)$, bien precedido de -s- ("samo). Incluye Uxama ('la muy alta') entre los topónimos formados utilizando

3 En su libro sobre los nombres de los pueblos de Álava Salaberri (2015: 257) recoge las opiniones de varios autores sobre -ama, de manera que se remite a dicho resumen a quienes deseen conocer las aportaciones sobre la materia que no se mencionan aquí. 
sufijos con - $m$ - y, posteriormente, cuando estudia lingüísticamente la Álava pre-romana y romana, se refiere a Zezama (1970: 189), Ledama (ibid., 191) y Lezama (ibid., 192) como formaciones con estructura pre-romana indoeuropea de tipo superlativo.

Agud (1973: 45-46, 67) considera llamativo el hecho de que los nombres más significativos (Beizama, Arama, Arakama...) se hallen en el corazón de Gipuzkoa, aunque haya en Bizkaia también alguno (Lezama...) en la misma área de -ika, -aka, y en Navarra (en la zona opuesta a -ika, -aka) esté, por ejemplo, Ultzama. En su opinión, quizá habría que pensar en un sufijo -zama para-Ultzama y Lezama. Aporta un plano (conjunto con los sufijos -ika y -aka) donde localiza los siguientes topónimos no citados por Mitxelena: Sarama, Ezama (2) (caserío) y Elama (barrio).

Irigoien (1975: 96-97), en su estudio de los nombres de los seles de la Colegiata de Cenarruza (BI), dice que es posible que tanto Zama- (Zamakola, Zamakoa...) como Chamo- estén relacionados con nombres antiguos de la península de tipo indoeuropeo, tales como Segisama, Segisamo[n], Uxama, Letisama y, posiblemente, también Lezama, así como con el nombre del sel Lexamona, formado con toda probabilidad sobre Lexamo.

La historiadora Esteban (1990: 426-427), en sus tesis sobre el País Vasco atlántico en época romana, aporta un listado con topónimos de Bizkaia, Gipuzkoa y Navarra terminados en -ama, sumando al corpus de los inventariados hasta entonces los topónimos guipuzcoanos Amiama, Bedama y Txarama.

Para Gorrochategui (1993: 122) uśamus (una de las cuatro leyendas monetales que abarcan una extensa zona limítrofe del País Vasco) recibe una explicación satisfactoria desde el lado céltico. El étnico de la ciudad de Uxama sería lingüísticamente una forma de superlativo a partir del indoeuropeo "ups-m.mo- ('la más elevada'), con paralelos precisos en otras lenguas célticas. De este nombre celta procedería, no sólo el actual de Osma [de Valdegovía], sino también, muy posiblemente, el navarro Ultzama. Aunque la explicación etimológica completa de muchos de los frecuentes topónimos vascos en -ama, como Beizama, Lezama, Zegama, etc., tenga sus dificultades (< ¿Segisama?), es sugerente a su modo de ver (Gorrochategui, 2009: 75) pensar que la terminación -ama remonta al morfema céltico de expresión del superlativo.

En opinión de Untermann (2001: 202), el sufijo -isamo- coincide perfectamente con las marcas de superlativo de las lenguas celtas y del latín. Se da en el topónimo Letaisama (sobre monedas celtibéricas), así como en su correspondiente lusitano Bletisam(a), y (sin - $i$-) en los nombres de las ciudades Uxama y Rixama. Afirma que es frecuente en la antroponimia hispano-celta, sobre todo en la parte lusitano-gallega.

Prósper (2004: 186-189), quien analiza pormenorizadamente la toponimia del ámbito celta peninsular, en primer lugar, distingue los superlativos en *amo-, "-samo-e *-isamo-. De hecho, entre los ejemplos toponímicos conocidos del sufijo *-samo- estarían Uxama (hoy Burgo de Osma [SO], Osma de Valdegovía [A] y Osma [BI]), Osmo (Cenlle, Ourense), Ultzama y la leyenda monetal usamuz, todos del celtibérico ux-sama- / o- ('la realísima'). Sostiene Prósper (2005: 278-282) que entre los núcleos de población 
del área central de Celtiberia a los que se podría atribuir un origen en superlativos celtas se encontrarían, además, Luesma (Zaragoza, ZA) y Monesma (Huesca, HU); podría añadirse, en su opinión, el hidrónimo de Segovia (SEG) Eresma, procedente acaso de "e[p]er[a]isama («la más occidental»). También recoge (2005: 283) que en territorio vasco se ha atribuido, igualmente, el origen de cierto número de topónimos a la influencia celtibérica; sería el caso de Lezama (BI), probablemente procedente de *(P)letaisama (equivalente vasquizado de los numerosos Ledesma hispanos) y Beizama (GI).

Jordán (2004: 138-140) habla del sufijo *-mmo, con un significado originario de superlativo absoluto. Según su parecer, la secuencia -is-mmo dio lugar al celta (al menos insular) *-isamo. Así, las formas Sekisamos y Letaisama, por ejemplo, procederían de una formación del sufijo de superlativo -isamo- $<$ "ismmo-.

Salaberri (2005: 91; 2015: 319-320, 407, 419), finalmente, remarca que, a pesar de que en la toponimia mayor de Navarra los nombres, generalmente, son eusquéricos, hay alguno celta; pone como ejemplos Cascante, Sesma y Ultzama. Menciona también Berama (despoblado, Satrustegi, NA) y destaca, de igual manera, que los topónimos de origen céltico han evolucionado según las reglas del euskera (Lezama) o del romance (Osma), dependiendo de la lengua mayoritaria de la zona donde se sitúan.

\section{INVENTARIO}

\section{$2.1^{4}$. Amiama}

Caserío del Goierri guipuzcoano, incorporado al inventario por Esteban (1990: 427). Está en una ladera ${ }^{5}$ de Gaintza próxima al núcleo principal de población y se documenta para el siglo XIV: Lope de Amiama, Martin de Amiama (1399; Ayerbe y San Miguel 2013: 12), Maria Amiama (1634, AHDG1; Altzaga), Amiama (1857, casa de labor; NPG: 93). Hoy en día se pronuncia coloquialmente Amima. En Amorots-Succos (Baja Navarra) existe el oicónimo Amiasorhoa (2014, IGNF), si bien, en ese caso, no se identifica a primera vista ningún sufijo, con meridiana claridad al menos.

Es difícil no sucumbir a la tentación de ver en Amiama una base antroponímica, como, por ejemplo, Ammia / Ammius (Ammia Arocia, León [LE]; Ammia Caelionica, Parres, AS; vid. Hesperia-BDLP, onom. 1066; Solin y Salomies, 1994: 14), máxime cuando en Zegama existe el caserío ${ }^{6}$ (y barrio) Amiao (Amiano). Para Albertos (1985:

4 Dígito con el que aparece el topónimo en el plano n. ${ }^{\circ} 1$.

5 Orientación este. Cerca del paraje Ezintzio y la ermita de San Martín. Coordenadas UTM (30N ETRS89): x: 571414,30; y: 4766981,8; z: 385. Para Álava, Bizkaia y Gipuzkoa se ha consultado la Infraestructura de Datos Espaciales de Euskadi (GeoEuskadi) y para Navarra el Sistema de Información Territorial de Navarra (SITNA).

6 Amiano, Pedro de (1579, ARCHV3; Zegama), Amainoerdicoa (1841, AHZ2), Amiano (1857, barriada, NPG: 16), Amiña Erdicoa, Amiñau-Aldea (1945, AHZ3). 
265), Ammia / Ammius sería un nombre personal indígena bien representado en la zona astur, si bien, podría darse, según ella, homofonía con un nombre latino.

\subsection{Arakama}

Al igual que en el caso anterior, los caseríos Arakama (Arakamagarakoa y Arakamazpikoa) se ubican en el Goierri guipuzcoano, concretamente en Zegama. Están en una ladera $^{7}$ situada en el fondo de un valle y la primera referencia es del siglo XVII: Martín Aracama (1606, AHDG2; 1815; AHZ1), Aracamas (1857, barriada, NPG: 16). Parece ser de la misma serie toponímica que el conocido monte Araka de Vitoria que, según Salaberri (2012a: 215), puede tener su origen en *(villa) Aracana (<Aracus). En Deba (GI) existe el caserío Arakistain (Araquistáin, 1857, casa de labor, NPG: 20).

Al igual que en Amiama, la base podría ser un antropónimo, en este caso el nombre indoeuropeo pre-latino Aracus / Araca, documentado, por ejemplo, en un ara de Eslaba (Araca Marcella, Huarte 1997: 167; Hesperia-BDLP, onom. 965; NA) y tal vez relacionado con Araica Arai (gen.) de Kontrasta (Elorza Guinea, 1967: 136; A; cfr. Solin y Salomies, 1994: 20; Hesperia-BDLP, onom. 966). Albertos (1966: 30) se refiere a Aracus como divinidad hispánica (vid. Arama).

\subsection{Arama}

Pequeño municipio del Goierri guipuzcoano, con su núcleo principal en un rellano ${ }^{8}$ sobre el río Oria. Aparece por primera vez en las fuentes escritas el siglo XIv: Iohan Lopez d'Arama (1384; Roldán, 1991: 29), Arama (1399, collación; Ayerbe y San Miguel, 2013: 13). De forma análoga, en Pechón (Santander [SAN]) hay un arenal llamado Playa de Arama9 .

Mencionado varias veces por Mitxelena (AV, 39; 1960: 247-248; 1968: 485-486), Arama no es un nombre de lugar transparente. Es sugerente la posibilidad de relacionarlo con el topónimo alavés Araia (< *[H]araius, Asparrena; cfr. Munio Lopez de Arhaiburi, 1104, Rioja; vid. Salaberri, 2015: 82-83), pero, teniendo en cuenta la existencia del oicónimo Amiama (con hiato -ia- en la unión del sufijo y la base) parece difícil que la base sea Arai- (> *Araiama). Albertos (1970: 128) habla del antropónimo romano Araus, Arauus, atestiguado preferentemente en las regiones cántabras y astures ${ }^{10} \mathrm{y}$, por otro lado, relaciona el femenino romano Aunia Ara de Ilarduia (Hesperia-BDLP, onom. 1261; A) con Araka y Araia. Más adelante la filóloga leonesa (1985: 266) se refiere a

7 UTM: x: 557205; y 4759628; z: 315. Orientación este. No muy lejos de los caseríos Dirintia y del casco urbano.

8 UTM: x: 567904; y: 4768198; z: 165. Orientación oeste.

9 En Oloron-Sainte-Marie (Bearn, Francia), en el límite con Vasconia pero aislado geográficamente del conjunto de topónimos terminados en -(a)ma, está el municipio Aramits (eus. Aramitze); ¿Arama + -i(t)z?, cfr. Aldamiz, Lezamiz...

10 Asturias (La Lloraza, Soto de Cangas), León, Zamora (Villacampo), Palencia (Monte Cildad). 
Araius, Araica y Araca como variantes de Araus. Sea como fuere, al igual que en los dos topónimos anteriores (Amiama y Arakama), es probable que la base de Arama sea un antropónimo, relacionado seguramente con el genitivo Araica Arai de Kontrasta y el segundo elemento de Aunia Ara de Ilarduia.

\subsection{Aldama (4) /Aldamiz}

Hay, cuando menos, cuatro entidades geográficas con el nombre Aldama en Vasconia: un barrio de Amurrio (A), una casa en Zeberio (BI), un bosque (Aldamabaso) en $\mathrm{Mu}-$ xika (BI) y un paraje en Zuhatzu (Arakil, NA). Del barrio de Amurrio (ubicado en lade$\mathrm{ra}^{11}$ ) da fe López de Guereñu (1989: 30) y, por otra parte, también aparece a finales de la Edad Media como apellido (Alvaro de Aldama, 1458, procurador de tierra de Ayala; Goicolea, 2002: 80). La casa ${ }^{12}$ de Zeberio y el bosque ${ }^{13}$ de Muxika están recogidos en la base de datos de toponimia (en línea) de la Diputación Foral de Bizkaia y, finalmente, la ladera ${ }^{14}$ de Zuhatzu está inventariada en el volumen XIII de la serie dirigida por Jimeno Jurío Toponimia y Cartografía de Navarra (p. 122). En Gautegiz Arteaga (BI) se documentan, asimismo, los caseríos ${ }^{15}$ Aldamiz gojeazcoa, Aldamiz echebarria y Aldamiz andicoa en 1745 (Kerexeta, 1992: 354).

Tanto Aldama como Aldamiz son citados, entre otros autores, por Mitxelena ( $A V$, 347) y Salaberri (2015: 45, 86). A modo de ver de este último (ibid.: 62-63), a pesar de haber Alda- en ciertos topónimos que designan terrenos llanos, el nombre del pueblo alavés Alda (Valle de Arana) no es transparente ( $c f r$. Andamon, paraje, Campezo, A). De igual forma, Salaberri (2011a: 59-60) constata que en la mayoría de topónimos con -(i) $(t) z$ analizados por él la base es un nombre de persona, de manera que el topónimo resultante indica su hacienda o propiedad. De hecho, según el onomasta de Ujué, dicho sufijo se desligó pronto del étimo, se hizo independiente y se pudo añadir a bases antroponímicas foráneas e indígenas.

\subsection{Elama}

Regata $^{16}$ de la finca de Artikutza (Goizueta, NA), citada por Agud (1973: 67), donde se ubican las ruinas de una ferrería hidráulica $(400 \mathrm{~m})$, que existía ya para el siglo XIV (Elama, 1377; TCN-XLVII: 154). Es uno de los escenarios de las conocidas coplas de Trabuco ${ }^{17}$, estudiadas detalladamente por Perurena (2010: 29-31), quien en su libro sobre ellas recopila varias referencias históricas del topónimo.

11 Orientación sur UTM: 503546; y: 4768859; z: 485.

12 UTM: x: 522233; y: 4793510; z: 125.

13 Fondo de valle. UTM: x: 522309; y: 4793441; z: 75.

14 Orientación norte. No muy lejos de Berama. UTM: x: 591421; y: 479304; z: 910.

15 No lejos de Ozamiz. UTM: x: 529813; y: 4801867; z: 230.

16 UTM: x: 597943; y: 4781491; z: 400.

17 «Ongi ongi oroitu hadi zer egin huen Elaman» ('recuerda bien qué hiciste en Elama'). 
En la toponimia de Vasconia la secuencia inicial Ela- no es completamente desconocida; sirvan como botón de muestra los siguientes nombres de labrantíos alaveses recogidos por López de Guereñu (1989: 186): Elauri (1715; Uribarri Arratzua), Elagorri (1690; Maeztu), Elano (1792; Angostina, Bernedo) y Elamendi ${ }^{18}$ (1647; Ullíbarri-Arana). Además de lo anterior, en un epitafio sepulcral de Iruña de Oca (A) se lee el cognomen Elanus (Hesperia-BDLP, onom. 2358), que para Albertos (1970: 134-134) es un antropónimo romano basado en "el-, raíz que (con diversas ampliaciones) formaría nombres de animales y árboles, algunos de los cuales habrían pasado luego a designar también nombres de personas. Cabría la posibilidad, por lo tanto, de que Elama fuese una evolución de un hipotético*Elanama (Elan[us] + -ama), con caída de nasal intervocálica (característica de la lengua vasca) y posterior monoptongación de vocales abiertas en contacto.

\subsection{Erama}

Apellido incluido en la base de datos onomásticos eusquéricos de la Real Academia de la Lengua Vasca (EODA). En Tolosa Lema et al. (2002: 399) recogen la forma Eramaguirre en 1532 (lugar), pero, teniendo cuenta la existencia del caserío Ezamagirre en aquella localidad, a pesar de la probada competencia del transcriptor, dicha muestra es dudosa. Se trata, así pues, de un topónimo oscuro, que parece ser el doblete en -ama del topónimo castellano ${ }^{19}$ Eresma (<-isama; vid. Prósper 2005: 282) que aparenta haber sufrido síncopa de vocal postónica.

\subsection{Ezama (2), Entzama}

Citados ambos por Agud (1973: 67), los caseríos Ezama están en sendos municipios guipuzcoanos (Errezil y Tolosa) relativamente próximos entre sí. El primero, que en la actualidad presta su nombre a un barrio, está en una ladera ${ }^{20}$ y se recoge en el Nomenclator de la provincia de Guipúzcoa del año 1857 (Ezama, casa de labor, p. 31). El segundo, situado en otra ladera ${ }^{21}$, en este caso junto al río Oria, tiene una tradición documental más dilatada: Martin Miguell d'Eçama (1348; Roldán, 1991: 20), eglesia de Santa Luzia d'Eçama (1384; ibid.: 29), Ezama (1857, casa de labor; NPG: 105).

Por lo que respecta a Entzama, es preciso señalar que es un lugar de la sierra de Entzia (A) del que solo hay una referencia, del siglo xiv: Hençama (1418, otero alto; Goicolea, 1998: 79). Llama la atención la /h/ del comienzo (cfr. Harrama), que puede ser una adaptación gráfica para evitar la confusión del comienzo del topónimo (En-) con la preposición romance en. Con todo, tiene el aspecto de ser una variante de Ezama, surgida por repercusión de la nasal.

18 Mitxelena (1972a: 25) dice que acaso dé testimonio de la forma occidental elae, elai ('golondrina'), que -al igual que el vasco común enara- descendería de "eLana / "eNala (FHV, 326).

19 Hornillos de Eresma (Valladolid), Yanguas de Eresma (Segovia); cfr. Valderesma (Huesca).

20 Orientación nordeste. UTM: x. 566128; y: 4778248; z: 537.

21 Orientación oeste. UTM: 575853; y: 4777879; z: 123. 
En Arizala (Valle de Yerri, NA) se localiza el despoblado de Eza, documentado en los siglos XI y XII: Eça (1042; cenobio, iglesia, TCN-XXVI: 92), Sant Julani de Esa (1063, monasterium, Goñi Gaztambide, 1997: 44), Baztérreco Ardancea de Eça (1164, vinea; Lacarra, 1957: 37; Iratxe).

\subsection{Ozamiz}

Caserío de Gautegiz-Arteaga (BI) ubicado en una ladera ${ }^{22}$ sobre la ría de Urdaibai. Puede leerse en la fogueración de 1704 (Kerexeta, 1992: 136). Cfr. Aldamiz y Lezamiz.

\subsection{Ultzama (2) / Untzama (2) / Osma (2)}

Las primeras menciones del municipio y valle navarro de Ultzama son de los siglos XI-XII. Mitxelena (1969: 13, 31) recopila varias de ellas, que, en más de una ocasión, aparecen como apellidos: Enneco Azenariz de Uzama (1057), Iozama (1120), Uzama (1148), Petrus de Uzzama / Uzcama (1174). Existen más, como, por ejemplo, Fortunio Enecones de Vtzama (1087; Goñi Gaztambide, 1997: 70).

Del sel ${ }^{23}$ de Ultzama (Parzonería General de Gipuzkoa y Álava) se conocen dos muestras antiguas, una de 1418 (Uçama; Goicolea, 1998: 78) y otra de 1519 (Huçamagoytia; Pozuelo, 2010: 281). Se localiza en un rellano ${ }^{24}$ próximo a la cima del monte Txurruko punta. Llama la atención la /h/ de la segunda referencia (cfr. Entzama).

El paraje de Untzama, citado por Mitxelena (1969: 31), se ubica en un espolón ${ }^{25}$ situado sobre el casco (Elbarrena) del municipio de Ataun (GI). Arin, además de la forma oral Unzamako zelaye y la cita de 1733 Unzama (1928: 28), aporta una muestra (1956: 109) del año 1549: Uçama o Salese (borda de ganado).

También existe en Ermua (BI) una ladera ${ }^{26}$ (en una depresión del monte Urko) llamada Untzama. Aranberri (2001: 359) recopila numerosas referencias (1516, Vçama; 1626, Uncama; 1633, Ulçama; 1686, 1747, Unzama).

Finalmente, Osma es, por un lado, un pueblo ${ }^{27}$ (concejo) de Valdegovía (A) que, según recoge Salaberri (2015: 319), se documenta para el siglo XII (1172, Osma) y, por otro, un grupo de cuatro caseríos (1704, Osma Iturralde, Osma Ardanza, Osma aldecoa, Osma Arespe; Kerexeta, 1992: 179) situados en una ladera ${ }^{28}$ del monte

22 Cerca de la ermita de San Bartolomé y no lejos de Aldamiz. UTM: x: 526893 y: 4801510 ; z: 76.

23 Vid. Zaldua, 2015.

24 Orientación sur. UTM: x: 561354; y: 4751876; z: 902.

25 Orientación suroeste. UTM: x: 567626; y: 4762611; z: 308.

26 Orientación sur. En los aledaños se ubicaba la ermita de San Martín. UTM: x: 541311; y: 4781901; z: 341.

27 Situado en el fondo de un valle $(570 \mathrm{~m})$.

28 Orientación sureste. No lejos de la ermita de San Miguel. UTM: x: 536321; y: 4782700; z: 387. 
Zengotitagane (Oiz) que dan nombre un pequeño barrio de Mallabia (BI). Huelga decir que en Soria está el municipio de Burgo de Osma (Oxoma, c. 1239, civitas; Goñi Gaztambide, 1997: 515). De hecho, la muestra de Mallabia puede ser un ejemplo de traslado toponímico.

Mitxelena se fija en el topónimo Ultzama varias veces en su obra. En el artículo de 1960 (pp. 247-248) lo clasifica entre los de origen indoeuropeo y señala que Uxama tiene en Ulzama un claro representante en zona de habla vasca. Añade que Osma no ha salido regularmente de Uxama, puesto que - $a$ - postónica se conserva regularmente en los romances españoles. En otro de 1964 (p. 133) establece que la líquida anteconsonántica es efecto (reciente) de la repercusión de la nasal, con disimilación posterior (cfr. Untzama en Ataun). Insiste, de igual modo, en que Ultzama, de tener el mismo origen, continuaría más fielmente que Osma el nombre documentado en los textos clásicos. En un trabajo de 1968 (pp. 485-486) subraya que en Ultzama volvemos a topar con vasco - $z$ - (fonema por otra parte, más frecuente que -s-) y apostilla que es difícil no reconocer en dicho nombre de lugar el ubicuo Uxama, pidiendo que se compare con el celtibérico uśamus ('uxamenses').

Gorrochategui en su trabajo de 1991 (pp. 10-16) indica que el nombre de la ciudad que en alfabeto latino aparece como Uxama y se escribe en las monedas celtibéricas como uśama (étnico uśamus), en protocelta era *-uksama (*-ks->-xs->-ss-). Se trataría de un superlativo ("uks-ama) cuyo étimon indoeuropeo tenia una labial ("ups-). En su artículo de 1993 (p. 122) precisa que el nombre céltico Uxama es lingüísticamente una forma de superlativo a partir de indoeuropeo *upsm.mo- ('la más elevada').

En opinión de Untermann (2001: 202) el sufijo -isamo-, frecuente en la antroponimia hispano-celta (sobre todo en la parte lusitano-gallega) se da, por ejemplo, en el nombre de la ciudad Uxama.

Para Jordán $(2004: 77,139,189)$ el nominativo UXAMA, transcripción latina datable (c. 153 a C.), es un superlativo de *(o)ups- con el sufijo femenino -mma ('la muy alta'), de donde *(o)ups-ama > "uksma > usama [uxama], aunque, a su parecer, tampoco habría mayor problema en que el sufijo fuese "smma ("[o]ups-smma).

Prósper (2004: 186-189) piensa que entre los ejemplos toponímicos conocidos del sufijo *-samo- se encuentran Uxama, Osmo, Ulzama y la leyenda monetal usamuz, todos del celtibérico $u x$-sama-/-o- ('el/la más alto/alta', 'muy alto/alta') y basados en el indoeuropeo *Hup-. UXAMA estaría entre los topónimos hispanos de origen celtibérico con acento en la antepenúltima pero supuestamente sin síncopa hasta época romance. Más tarde $(2005: 178,197)$ habla del adverbio y preposición celta "uxs- ('arriba, alto, sobre'), presente en Usama / UXAMA.

Finalmente, Salaberri, en un estudio de 2005 (p. 91), clasifica Ultzama entre los topónimos de origen celta, al igual que Osma de Valdegovia (de Oxoma $<$ Uxama). En su libro de 2015 destaca que este último topónimo ha evolucionado según las reglas del romance, lengua mayoritaria de la zona donde se sitúa. 


\subsection{Bedama}

En Gipuzkoa hay dos seles con el nombre Bedama. El primero, documentado para 1385 (Ayerbe y Elorza, 2008: 18), está ubicado en una ladera ${ }^{29}$ (de un vallecito) de Errezil. Existió allí un caserío (1575; ARCHV2) que actualmente presta su nombre a un barrio (pronunciado coloquialmente Beama). El sel de Ataun también se sitúa en una ladera $^{30}$, pero aparece más tarde, en el siglo XVIII: Beama zelaye (1781; Arin, 1928: 92), Bedama (1826, redil; Arin, 1956: 102), Beama (barrio, caserio, sel ${ }^{31}$; Arin, 1928: 92; Ataun), Beama erreka (Arin, 1928: 85).

En Vasconia hay varios topónimos con la secuencia inicial Bed-. Más de uno parece de raigambre eusquérica, como Bedayça (1054-1076, locus; cerca de San Miguel de Aralar; Goñi Gaztambide, 1997: 40), Bedaran (1705, sel; TCN-XLVIII: 72, Leitza) o Bedaga (1493, paraje; TCN-XXIII: 79, Améscoa Baja-Valle de Yerri), pero, otras veces, en apariencia por lo menos, asemejan portar sufijos de origen latino, como en el caso de Bedua (caserío, barrio, Zumaia; < ¿*Bedona ${ }^{32}$ ?), por citar un ejemplo. Otra referencia interesante es el occitano Bedós (fr. Bedous), en el Valle de Aspe (Bedosse, 1128; Raymond, 1863: 26), posiblemente también de origen deantroponímico. Asimismo, es preciso señalar que tanto Albertos (1966: 152) como Prósper (2005: 189) hablan de los antropónimos mEDAMus (Caldas de Vizella, Portugal) y MEDAMA (Cisalpina, norte de Italia). Por otro lado, según se recoge en Hesperia-BDLP (Z.02.01.), en una lámina de bronce hallada en el yacimiento de Chicharroya (Novallas, ZA) se lee el sintagma acusativo sam bedam, cuyo significado estaría quizás próximo al campo de la minería.

\subsection{Berama}

Despoblado de Satrustegi (Arakil), bien documentado, ubicado en la vertiente ${ }^{33}$ norte de la sierra homónima: Jaun Sanso Acenariç de Berama (1134-1150; Martínez Díez, 1975: 202), Berama (1306; despoblado, Atadill, 1918: 30), Berema (1653; TCN, XIII: 105), Berama (1894; ibid.). Salaberri (2015: 320) aporta los nombres de los parajes Beramaundia, Beramatxikia y Beramaerrekaldea, entre otros. En Markina-Xemein (BI) hay un monte $(410 \mathrm{~m})$ llamado Beramo, que, a primera vista, parece el doblete con moción de género masculino (-amo) de Berama, pero, desafortunadamente, no tiene tradición documental conocida.

29 Orientación oeste. En el límite con Zestoa. UTM: x: 567386; y: 4783895; z: 402.

30 Orientación este. No muy lejos de la Mancomunidad de Enirio-Aralar y cerca del sel de Aietzio (Ayaçio, 1404; Aierbe y San Miguel 2013: 26; Ayecio, 1857; NPG: 86). UTM: x: 567901; y: 4759820; z: 474.

31 «Korta Txipi (= cortijo pequeño). 1404 sel de Corta chipia. Más tarde se llamó sel de Bedama».

32 Es desconocido si Bedoña (barrio, Arrasate) es de la misma serie. Mitxelena $(A V, 492)$ se hace eco de que Castro y Sachs (1935) sostuvieron que Bedoña y Begoña (BI), junto con la antigua Bedunia de los Astures y Bedoya (SAN), representaban derivaciones del celt. bedo- con el suf. -onia. Menciona los apellidos Bedua, Bedia (Vedia). Salaberri (2012b: 339) opina que en el caso de Bedoña el antropónimo de la base es Vedonius. Kerexeta (1992: 120) recoge en la fogueración de 1704 el caserío Bedoña de Elorrio («Antes era Bedoia, en 1575»).

33 UTM: x: 589640; y: 4750565; z: 600. No lejos de Aldama. 
Mitxelena menciona Berama varias veces. Partiendo de que Tovar reconoce el superlativo celtibérico ueramos, uoramos ('supremo', de "uper-amos) en las inscripciones de Peñalba de Villastar, el maestro de Errenteria compara Berama con dicho adjetivo (1960: 247-248; 1964b: 133). Albertos (1970: 162), por su parte, habla de la raíz indoeuropea "wer, "awer ('agua, lluvia, río') y Salaberri (2015: 320), basándose en el galo uer(o)('sur-, super-'), cree que Berama tiene un significado similar a Osma y a Ultzama.

Prósper (2004: 189), finalmente, cita el topónimo mayor Beresmo (Ourense) que relaciona con el testimonio epigráfico berisamo (Sta. Comba, ACO). Podría ser el doblete en -isamo de Berama / Beramo, pero, habida cuenta que en lengua vasca el cambio $V l V>V r V$ es conocido, no puede descartarse completamente que la base tuviera antiguamente una lateral ( $i *$ Belama? $>$ ¿Berama?).

\subsection{Ledama}

Solo hay dos referencias. La primera de ellas proviene de Albertos (1970: 191), que lo sitúa en Urrunaga (Legutio, A) el año 1654 y la segunda la aporta López de Guereñu (1989: 298); aunque el año es el mismo (1654), la localización es, en este caso, Salvatierra (A). En cualquier caso, según Albertos (1970: 191) Ledama sería un topónimo de estructura pre-romana indoeuropea, probablemente basado en un antiguo superlativo.

Es tentador relacionar Ledama con Ledesma (< *[p]letísama), pero Ledesma de la Cogolla (Logroño, LO) se documentada todavía como Letesma (con consonante medial sorda) en una donación del año 1076 y, como es sabido, a diferencia de las lenguas romances del entorno, las antiguas oclusivas sordas no han sonorizado en lengua vasca.

\subsection{Lezama (2) / Lezamiz}

Según recoge Salaberri (2015: 276), el barrio ${ }^{34}$ (antiguo pueblo) Lezama de Amurrio (A) se documenta para el siglo xiI, y es también conocido que el municipio homónimo del Txorierrij3 (BI) es citado, igualmente, en la Baja Edad Media. Por lo que respecta al caserío Lezamiz de Fruiz (BI) (Lezama + -i[t]z) se recoge en la fogueración de 1745 (Kerexeta, 1992: 346). Está situado en la ladera ${ }^{36}$ de una colina ubicada en el fondo de un valle.

Se ha escrito bastante sobre el topónimo Lezama. Salaberri (2015: 257 y 319-320) realiza una síntesis del estado de la cuestión, de manera que no ha lugar repetir aquí lo que ya resume perfectamente el profesor de Ujué. En cualquier caso, cabe destacar que en $A V$ (39) Mitxelena apunta que, si su - $z$ - denotase una africada, podría ser el equivalente de Letisama,

34 UTM: x: 502031; y: 4764799; z: 304.

35 Según la IDEA en Armiñon (A) hay un campo llamado Lezama, pero es probable que se trate de Lezana, pueblo de Treviño (López de Guereñu, 1989: 303) y labrantío de Hereña (1709; ibid.).

36 Orientación sur. UTM: x: 516526; y: 4795933; z: 74. 
Ledesma. Así, lo compara con el antiguo vizcaíno betesegi (mod. betsegi, 'vaca con cría', de esegi 'colgado') y sugiere la evolución Letisama / "Letizama > "Letzama > Lezama. En la misma obra (347), pone como ejemplo (entre otros) el doblete Lezama / Lezamiz al afirmar que el sufijo $-i(t) z$ parece haberse empleado bastante, en tiempos relativamente recientes, para formar derivados de otros topónimos o apellidos. Más tarde, en su artículo de 1960 (pp. 247-248), señala que Ledesma (cfr. Osma) no ha salido regularmente de Letisama, puesto que - $a$ - postónica se conserva regularmente en los romances españoles.

Albertos (1970: 192) analiza Lezama junto a Lezana y Leza. Se trata, en su opinión, de un topónimo de estructura pre-romana indoeuropea, con una raíz no bien determinada, más el sufijo -ama o -sama de superlativo.

Para Gorrochategui (1991: 7, 10) el término celtilbérico Letaisama presenta serias dificultades. Por un lado, el conocido superlativo de nombre de lugar presenta un ejemplo problemático de lail, ya que no se sabe si se trata de un verdadero diptongo o más bien es una ilusión grafica en lugar del esperado /letisamal ( < "pleta-is-amo-). Estima que se podría pensar en una influencia (tal vez no fonética, sino solo gráfica) del grado positivo (quizá celtibérico *letano- > leta-isamo-). En segundo lugar, estaría la cuestión de la etimología, ya que normalmente se supone un superlativo *pleta-isamo-, sobre la misma base que el grado positivo (<* pleta-no-). Este adjetivo presenta una relación irregular entre positivo y grados comparativo y superlativo, en el sentido de que estos están formados sobre la raíz, pero no directamente sobre el grado positivo. El tratamiento en celtibérico debería haber sido idéntico ("Lit-isama), por lo que habría que admitir un étimo con grado pleno ("plet-isama).

Prósper (2004: 189) clasifica *(P)letáisama > Letáisama / BLETISAMA > Ledesma entre los topónimos hispanos de origen celtibérico con acento en la antepenúltima pero supuestamente sin síncopa hasta época romance. Según dicha autora (2010: 217), Ledesma es un topónimo bastante extendido en la actualidad en la zona central y septentrional de la península. Se da en Soria, Salamanca, Rioja e incluso en A Coruña; hay, además, una (Cabeza) Ledesma en Asturias, que querría decir «la más/muy ancha o extensa» y provendría de un superlativo celta *(p)letísama, que se atribuye a la raíz indoeuropea *pleth-. Si en el área occidental hallamos un número creciente de casos que continúan un *(p)letísama, en celtibérico contaríamos con una forma transcrita Letaisama en la epigrafía monetal. Esta forma se correspondería con la localidad de Ledesma de la Cogolla (LO), documentada todavía en una donación del año 1076 como Letesma, con consonante medial sorda. La ligera diferencia formal entre topónimos geográficamente distantes como BLETISAMA y Letaisama hablaría de una alternancia morfológica condicionada por la existencia de, cuando menos, dos variedades geodialectales (Prósper, 2005: 278).

En opinión de Jordán (2004: 140, 185) es una forma de superlativo a partir de un positivo (*letaiza < *letaida). Propone una forma de partida *pleta-id-sama, de donde "letaissama > letaisama. La primera parte (o raíz) "pleth- ('extenderse') sería una formación frecuente en la toponimia celta. Al tema pleta- se le añadiría un sufijo -id-, dando lugar a un adjetivo en grado positivo ('la llana'), siendo su correspondiente superlativo letaisama ('la muy extensa').

\section{0}


Finalmente, Salaberri (2015: 256), después de reconocer que tiene un origen oscuro para él, afirma que el topónimo mayor Leza (A) parece exigir un étimo *Letia o "Lecia y apostilla que no sabe si tiene alguna relación con Lezama (de origen céltico), pero tampoco descarta esa posibilidad explícitamente. Con todo, Salaberri (ibid.: 419) clasifica Lezama entre los nombres de lugar que han evolucionado según las reglas del euskera (cfr. romance Osma, con síncopa de la postónica), lengua mayoritaria en su día de la zona donde se sitúa.

Mitxelena condiciona el étimo Letisama / "Letizama $>$ "Letzama $>$ Lezama a que su - $z$ - denote una africada, pero los testimonios orales recogidos por Irigoien (1972: 216) van en contra de esa lectura (cfr. Ezama...). En ese sentido, cabe la posibilidad de que Lezama sea la versión eusquérica de Lesma ${ }^{37}$ (apellido, SEG; Hoya Lesma, Carabaca de la Cruz, Murcia); exige que haya habido síncopa de la vocal breve postónica en ese último nombre de lugar ("Lesama > Lesma, Lezama), pero puede ser la solución más económica.

\subsection{Zegama}

Las primeras noticias del conocido topónimo guipuzcoano, cuyo casco urbano está en la parte baja de la cabecera del río Oria, son del siglo xiv: Ladrón Martínes de Çegama (1384; Díez de Salazar Fernández 1985: 127), Çegama (1384, vezindat de; AA. VV., 1996: 226). En la actualidad coloquialmente se pronuncia Zeama.

Al margen de su origen, en Vasconia son pocos, muy pocos, los nombres que comienzan con la secuencia Zeg-; Zegamendi es uno de ellos (cima, IDEA; Iruña de Oca [A]). Sin embargo, en los territorios limítrofes a Vasconia hay varios topónimos emparentados probablemente con la raíz indoeuropea "seg(h)-; dos muy conocidos son Ejea de los Caballeros (ZA), que, según puntualiza Velaza (2009: 615), viene de Segia (forma latina de Sekia) y Sasamón (municipio, BU), cuyo origen está en Segisamo / Segisama. Este último topónimo aparece en leyendas monetales $(S e k i S a m o S)$ con signario epicórico (Fernández Palacios, 2002: 69) y en varios testimonios epigráficos latinos: Segisami (Hesperia-BDLP onom.4737; Cubillas de Rueda, LE), Segisamo (Hesperia-BDLP, TO.03.01suspecta; Piloña, AS), Segisama Brasaca (Hesperia-BDLP; TO.03.01suspecta; Tarragona). De hecho, Mitxelena (1960: 247-248; 1968: 485-486) incluye Zegama entre las muestras de topónimos vascos de origen indoeuropeo en -ama y pide que se compare con Segisama ${ }^{38}$.

Albertos (1966: 201), cuando analiza el genitivo Segei (Hesperia-BDLP, Onom.4705) de Castandiello (AS), subraya que ese nombre contiene el radical "segh- ("seghi- 'sujetar, vencer', "seghos- 'victoria'), a su parecer, uno de los más fecundos en la onomástica

37 Cfr. Lesna (piedra, paraje; NGBE, Corduente, Guadalajara) y Valdeliesma (barranco; NGBE, Mequinenza, Huesca).

38 En AV (39) compara Leguizamón con Segisama / Segisamo(n). 
personal indoeuropea, especialmente en la celta y en la germánica; en celta estarían atestiguados Segamo, Segobriga, Segontium y Segeia, entre otros. Respecto al genitivo Segisami, la misma autora (ibid.: 202) indica que es un nombre con sufijo de superlativo -samo, y que los topónimos celtibéricos Segisama y Segisamo serían formaciones paralelas, también basadas en el radical "segh. Menciona igualmente Segius (ibid.) de San Juan del Monte (Aranda de Duero, BU), pero no da más detalles (cfr. Segius, Solin y Salomies, 1994: 166).

También Agud (1973: 45), incluye Zegama en su listado de designaciones indoeuropeas; Untermann (2001: 201-203), por su parte, ve en el comportamiento del segmento seg- un área cerrada y bien delimitada que coincide aproximadamente con la distribución geográfica de las inscripciones celtibéricas. Coincidiría, además, con la extensión de los antropónimos que contienen la raíz seg-, de manera que fuera de dicha área aparecerían solamente en unos pocos lugares. Aporta una lista de nombres con la base seg-, en la que se pueden leer Segisama Brasaca (no identificada), Segisama Iulia (ciudad de los Vacceos), Segisamo y Segisamunculum (al este de Briviesca, BU). A la vista del sufijo que lo acompaña, no duda de que el elemento seg-pertenezca al léxico celta.

Finalmente, Jordán (2004: 35) opina también que Zekia (Ejea de los Caballeros), podría tener un étimo indoeuropeo "segh- ('coger', 'tener'), que derivaría a un significado 'vencer' en celta y que sería corriente en la toponimia de este pueblo. Cree (ibid.: 139-140) que Sekisamos es conflictiva debido a la sibilante intervocálica que presenta; procedería de una formación con un sufijo de superlativo -isamo- $<{ }^{*}$-ismmo-. De la raíz "segh-surgiría un tema segho- ( > sego- en celta) que acabó teniendo el significado de 'victoria'. De hecho, en la onomástica ésta sería la forma mayoritariamente utilizada en composición, aunque habría otras. En cambio, en las formas derivadas la base sería precisamente "sege-; Sekisamos podría explicarse quizá a partir de *seg(e)-id-smmo (donde el grupo $-d s->-s s-y$ posiblemente $>-s-)$. En suma (ibid.: 195), propone para sekisamos una forma originaria de superlativo *seg(e)-id-smmo (la misma forma de superlativo que para Letaisama) pero en masculino, esta vez sobre la base *sego- referida a la ciudad ('la muy victoriosa').

\subsection{Zezama}

El raso $^{39}$ de Zezama está en la sierra de Entzia (A) y sus referencias proceden de Barandiaran, Madinabeitia y Redondo (Cezama, Zizama; Raso y Canteras de piedra, Majada pastoril; 1990: 102), de López de Guereñu (Cezama, cantera de piedra; 1989: 153; Bikuña) y de IDEA. También Albertos (1970: 189) se hace eco de Cezama (Bikuña), donde ve una formación de tipo superlativo en un topónimo de estructura pre-romana indoeuropea. 


\subsection{Beizama}

Municipio guipuzcoano, con el núcleo principal ubicado una en ladera ${ }^{40}$. Se documenta el siglo XIV: Beyçama (1384; vezino de; Roldán 1991: 29), Miguel de Beyçama (1499; Lema et al., 2002: 261). Es uno de los ejemplos que pone Mitxelena (1964: 133; 1969: 31) cuando diserta sobre nombres de lugar no explicados dentro del vasco mismo (vid $\$ 5.3$.$) .$

\subsection{Legizama / Legizamo}

Legizama es un barrio de Zuaza (Ayala, A), ubicado en una ladera ${ }^{41}$, que, según recogen Galé, Gorrotxategi y Mugurutza (2013: 308), se cita ya en 1514 (Leguyçama). De forma análoga, en Deusto (Bilbao) y Etxebarri (BI) hay constancia de la existencia de sendos caseríos con el nombre Leguizamon; ambos aparecen en la fogueración de 1704 (Kerexeta, 1992: 103 y 112). Existe igualmente el apellido Leguizamo(n), con un foco en la costa oeste de Gipuzkoa: Tristán de Leguiçamo (1504, Elorza Maiztegi, 2009: 198; Zumaia), Tristán de Leguiçamo / Leguiçamon (1507; ibid.: 229; Zumaia), Tristan Dias de Leguiçamo (1506; Fernández, Montecelo y Herrero, 2007: 168; Mutriku). Se trata de uno de los pocos casos de doblete-izama / -izamo en Vasconia (cfr. Berama / Beramo).

\subsection{Leizama / Lexamona}

Leizama solo consta como apellido, en la mayoría de las muestras en una zona y época concretas: Rodrigo de Leyçama (1455; Lema et al., 2002: 195; Deba), Marina de Leizama (1500; García Fernández, 1999: 349; Getaria), Vicente de Leiçama (1583; Odriozola, 1998: 128; Zumaia), Biçente de Leyçama (1584; Murugarren, 1997: 238; Zumaia), Viçente de Leyçama (1620; Barkham, 1997: 222; Zumaia). Asimismo, en una cita de 1523 se habla de Martin Sanz de Leizama, vecino de Plasencia de Vizcaya (ARCHV1). Vistas las fuentes, las fechas y la distribución geográfica de las citas, aunque no imposible, se antoja difícil que se trate de una concatenación de errores $(<¿$ Beizama?, ¿Lezama?). Desgraciadamente, no se testimonia como topónimo. De confirmarse su autenticidad, estaríamos, como en el de Beizama, ante un ejemplo de conservación del diptongo /ei/ (cfr. eus. Leizardi, Leizaso, Leizartza, Leizarrate > Lizardi, Lizaso, Lizartza, Lizarrate).

El primer testimonio del sel ${ }^{42}$ de Lexamona (Markina-Xemein, BI) es del año 1388. Lo recoge Irigoien (1975: 86, 96-97), para quien es posible que Lexamona esté relacionado con nombres antiguos de la península de tipo indoeuropeo, tales como Segisama, Segisamo[n], Uxama, Letisama y posiblemente también Lezama. En su

40 Orientación sur-este. $490 \mathrm{~m}$.

41 Orientación sur. UTM: x: 495264; y: 4771462; z: 270.

42 En la zona de Amallo. 
opinión, Lexamona estaría formado con toda probabilidad sobre Lexamo, como Barcelona lo está sobre Barcino. Lexamona se documenta más tarde también como Lexamea, lo que podría suponer un "Lexama más el artículo - $a$. El académico vizcaíno es de la opinión de que, quizá, también la /x/ de Lexamona haya sido africada [ts], de manera que se trataría de algo así como un antiguo *Letisamo. Cabe solo añadir a la aportación de Irigoien que el grafema / $/$ / podría indicar, acaso, un antiguo "Leizamona (cfr. vizc. lexar 'fresno'; vid. Leizama). Queda por aclarar el origen de la secuencia final -(o)na.

\subsection{Lizama}

Es el primero de un grupo de seis nombres cuya relación con la terminación -ama presente en los topónimos precedentes no está del todo clara, además de por razones estrictamente lingüísticas (vid. $\$$ 4.3.), en muchos casos debido a la escasez de testimonios escritos o a su ubicación geográfica. El primero de ellos es Lizama, acequia ${ }^{43}$ de Cintruénigo (NA) cuyas únicas citas por escrito son de 1892 y 1925 (Brazal de Lizama; TCN-IV: 35). Como apellido se documenta en Corella (NA) en 1565 (Pedro de Lizama, AGN1) y está incluido en la base de datos onomásticos eusquéricos de la Real Academia de la Lengua Vasca (EODA). Es abundante en Zaragoza y Teruel.

\subsection{Harrama}

El antropónimo Gonzalvo Garceiz de Harrama aparece, una sola vez, en el Becerro Galicano de San Millán de la Cogolla (UPV-Galicano), concretamente el año 1087 (f. 153v-154r; cfr. Serrano, 1930: 272). Llama la atención la /h/ inicial, ya que se trata de uno de los pocos casos del inventario contemplado en este trabajo que lleva dicho grafema ${ }^{44}$ (cfr. Hençama, Huçama), de manera que puede ser una adaptación gráfica para evitar la confusión de la vocal media del comienzo con la preposición romance $a$. Al margen de la presencia de la /h/, también la vibrante múltiple es excepcional, a lo que hay que añadir que solo se documenta una vez, lo que obliga a considerar la posibilidad de que se trata de una desfiguración del topónimo Arama.

\subsection{Santiama}

Hidrotopónimo $\left(\right.$ río $\left.^{45}\right)$ de Peñacerrada $(\mathrm{A})$, cuya única referencia documental (Santiama, 1660) es aportada por López de Guereñu (1989: 437). Aparece también en IDEA. Teniendo en cuenta que el propio López de Guereñu (1989: 533) recoge allí mismo un despoblado llamado Aima (documentado desde el siglo XI), su relación con -ama es dudosa $(<$ ¿*Santaima?, ¿por metátesis?).

\footnotetext{
43 UTM: x: 600843; y: 4658921; z: 405 m.

44 Cfr. Mitxelena (1982: 303).

45 UTM: x: 525344; y: 4722535; z: 797.
} 


\subsection{Sesma}

Municipio navarro, con el núcleo principal situado en la vertiente sur de una colina y que desde las primeras citas documentales medievales aparece con la misma forma (cfr. Campo Sesma, 1703; TCN-XIX: 134; Lodosa, NA).

Prósper (2004: 189) cree que el epíteto de la dedicación a NAVIAE SESMACAE ${ }^{46}$ de Galicia deriva de un topónimo que ha sufrido (tal vez con independencia de la adición del sufijo con velar), los pasos "segh-is-mma > celta común "segísama > hispano-celta occidental "sesama (por desaparición condicionada de - $g$ - entre vocales palatales) > "sesma > (por síncopa de vocal breve postónica; cfr. Segisamo [Piloña, AS] y Segisama [Tarragona]).

En la misma línea, Salaberri (2005: 91), al referirse a los topónimos celtas en la toponimia mayor de Navarra, afirma que Sesma (derivado de la raíz "seg[b]-, 'victoria') y Zegama pueden ser paralelos (-isama /-ama).

Sin embargo, habida cuenta que, según el Diccionario de la Real Academia Española, los términos sesma / sesmo ('sexta/o', 'sexta parte') se han empleado para referirse a grupos de pueblos asociados (en Teruel, por ejemplo, existen, entre otras, la Sesma de la Trasierra y la Sesma del Campo de Gallocanta), no se puede descartar definitivamente que tenga origen latino (cfr. quinto / quinta, quintana).

\subsection{Txarama}

Nombre de un caserío (y barrio) de Leaburu ${ }^{47}$ (GI) que, atendiendo la tradición documental, parece haber sufrido la palatalización de la sibilante inicial: Juan de Sarama (1729; AHA, Tolosa), Charama (barrio, 1829, ACZ), Condecharama (1857; casa de labor, barrio; NPG: 99), Fermin Sarama Sarama (1891; AHDG3; Tolosa). En Pedroso (SAN) existe un arroyo llamado Saramillo, que, a primera vista, asemeja ser un diminutivo de Sarama.

\subsection{Zalama (3)}

Hay, cuando menos, tres entidades geográficas con la denominación Zalama en Vasconia. La primera de ellas es una cumbre ${ }^{48}$ de la sierra de Ordunte, a caballo entre Bizkaia, Burgos y Santander. Fernández Palacios (2002: 1335) dice que se documenta como Çamala en 1666 y Zamala en 1863. La segunda es un paraje ${ }^{49}$ de AmillanoEchávarri (Allín, NA) que aparece en 1620 (Çalama; TCN-XXIII, 33, 67). La tercera

46 Procedente de un lugar incierto.

47 UTM: x: 575684; y: 4773520; z: 105. A diferencia de Zalama (vid. 2.24) Txarama no está, en la periferia del territorio del euskera.

48 UTM: x: 466239; y: 4775755; z: 1.335.

49 UTM: x: 575891; y: 4730363; z: 496. 
referencia viene de Álava, concretamente de Oteo (Campezo); es otro paraje $\mathrm{e}^{50}$, cuya primera cita es de 1708 (López de Guereñu, 1989: 510). Es preciso subrayar que las tres localizaciones de Zalama están en la periferia del territorio del euskera.

En Avellanosa de Muño (BU) existe el sitio denominado Zalama (NGBE) y en Villafranca Montes de Oca (BU) el arroyo Vallizalama (NGBE). Igualmente, en Torrecilla Sobre Alesanco (LO) y Sacramenia (SEG) hay sendos lugares llamados Valdezalama (NGBE). De igual modo, no muy lejos de Ejea de los Caballeros, en Luna (ZA), se conoce el topónimo Celama (NGBE) y en Aguilar de Campoo (Palencia) y Qintana del Marco (LE) sendos ejemplos de Valdecelama (NGBE). En León tenemos, finalmente, la localidad de Salamón, que, tal vez, podría ser una especie de doblete de *Salama (cfr. Legizama / Legizamo[n]).

Según Albertos (1970: 198), en la onomástica hispánica estarían bien atestiguados los nombres basados en Sal-, Sala- (indoeuropeo *sal[a]), pero según Fernández Palacios (2002: 821) la explicación más plausible es la que ve un étimo árabe.

\section{DISTRIBUCIÓN TERRITORIAL}

3.1. En la Vasconia aquitana no hay nombres de lugar con la terminación -ama. El límite nororiental de la zona de la Vasconia ibérica donde hay testimonios de topónimos terminados en -ama lo define la línea imaginaria que une Elama y Ultzama o, dicho de otra de manera, al este de Pamplona no hay ningún testimonio ${ }^{51} \mathrm{y}$, de forma análoga, al sur de la capital del antiguo reino hay muy pocos; de confirmarse su autenticidad, el más meridional sería Lizama. Si se deja al margen ese último testimonio (y también, acaso, Sesma), el límite sur del territorio de -ama lo delimita la línea trazada entre Zalama (Allín y San Román de Campezo) y Santiama. Puede dibujarse una segunda topoglosa meridional a través de las sierras de Andimendi (NA) y Entzia (A), que delimitaría, precisamente, el espacio con mayor concentración de ejemplos.

El límite occidental puede resultar difuso a primera vista, ya que el topónimo más al oeste es Zalama (Carranza), que está aislado. Ahora bien, si prescindimos de este testimonio, la topoglosa occidental podría delinearse uniendo Lezama (BI), Legizama y Osma (A). Los ejemplos alaveses más occidentales están, por lo tanto, en la zona exterior de la provincia (y de Vasconia), muy cerca de la provincia de Burgos.

En el noreste de Gipuzkoa no hay topónimos terminados en -ama, ni tampoco en el Alto Deva. Por otro lado, en la zona costera no hay muchos testimonios; los únicos son Aldamiz y Lezamiz (Gautegiz-Arteaga), que son también los topónimos más

50 UTM: x: 551951; y: 4729724; z: 691.

51 En Huesca está Lozama (vid. \$3.4.). 
septentrionales ${ }^{52}$. En Navarra, territorio principal de Vasconia, hay pocos ejemplos, lo mismo que en el sur-suroeste de Álava y Bizkaia.

El territorio donde son más abundantes los ejemplos de -ama es Gipuzkoa, máxime si se tiene en cuenta la superficie de la provincia. Ahora bien, no se distribuyen de manera uniforme; las muestras se concentran entre las cuencas de los ríos Oria y Urola. Esta zona se prolonga, allende la divisoria de aguas, hasta la cuadrilla de Salvatierra-sierra de Entzia (A) y Sakana (NA). En suma, la mayoría de los topónimos en -ama se concentra en el triángulo Errezil (GI)-Entzia (A)-Arakil (NA), en cuyo centro está el Goierri guipuzcoano.

Debido al corto número de testimonios ${ }^{53}$, poco o nada se puede concluir de la distribución de los nombres con -isama, salvo que aparecen en Álava (Legizama), Bizkaia (Lezama) y Gipuzkoa (Beizama). Finalmente, es preciso subrayar que los testimonios de -ama $+-i(t) z^{54}$ se concentran en las proximidades de la ría de Urdaibai (BI) y no se conoce ningún topónimo con la secuencia *-izamiz.

3.2. Como dice Gorrochategui (1993: 114), el análisis y la correcta asignación de los topónimos de un territorio puede ofrecer luz sobre épocas en las que faltan fuentes escritas, en especial si se descubre que una gran cantidad de nombres forma un conjunto homogéneo de designaciones toponímicas que no tienen explicación en la lengua hablada por la comunidad que los utiliza, sino en alguna otra lengua que hubo de hablarse en la zona en épocas prehistóricas.

En la línea de Mitxelena (1982: 304), quien recuerda que no basta con razones etimológicas para concluir que los nombres permiten inferir con certeza la lengua de sus portadores, Gorrochategui (1993: 122) matiza que no se puede identificar mecánicamente un área onomástica con un área lingüística, pero reconoce, a su vez, que se trata en muchos casos de una extrapolación verosímil y muy razonable, que de no ser verdad fallaría solamente en el hecho de suponer en uso una lengua que quizá se hubiera extinguido cierto tiempo atrás.

De hecho, Mitxelena (1982: 304, 305) afirma que los nombres de lugar (más los nombres de persona) hacen inevitable la conclusión de que hubo en zonas alavesas núcleos de población de lengua indoeuropea, al parecer céltica. Este elemento indoeuropeo se impuso, sin llegar a cubrirlo, por encima de un sustrato éuscaro. Concluye, en cualquier caso, que es asombroso que el número de préstamos indoeuropeos pre-latinos sea tan corto en Vasconia y que haya tan poca toponimia de ese origen.

52 Leizama se documenta como apellido, sin que se conozca su procedencia exacta.

53 Tampoco son abundantes en Vasconia los topónimos en -amo e -isamo; de momento, no se conoce ningún testimonio seguro en Gipuzkoa y en Navarra (¿Andamo[n]?, Genevilla, cerca del límite con Álava.). La mayoría de las muestras se concentran en Bizkaia (Legizamo, Zaratamo, Beramo, Orizamo) y el norte de Álava (Arkamo, Godamo). Con todo, parece que los terminados en -amo son menos que los que tienen -ama.

54 No parece que haya ningún caso de $-a m o+-i(t) z o-i s a m o+-i(t) z$. 


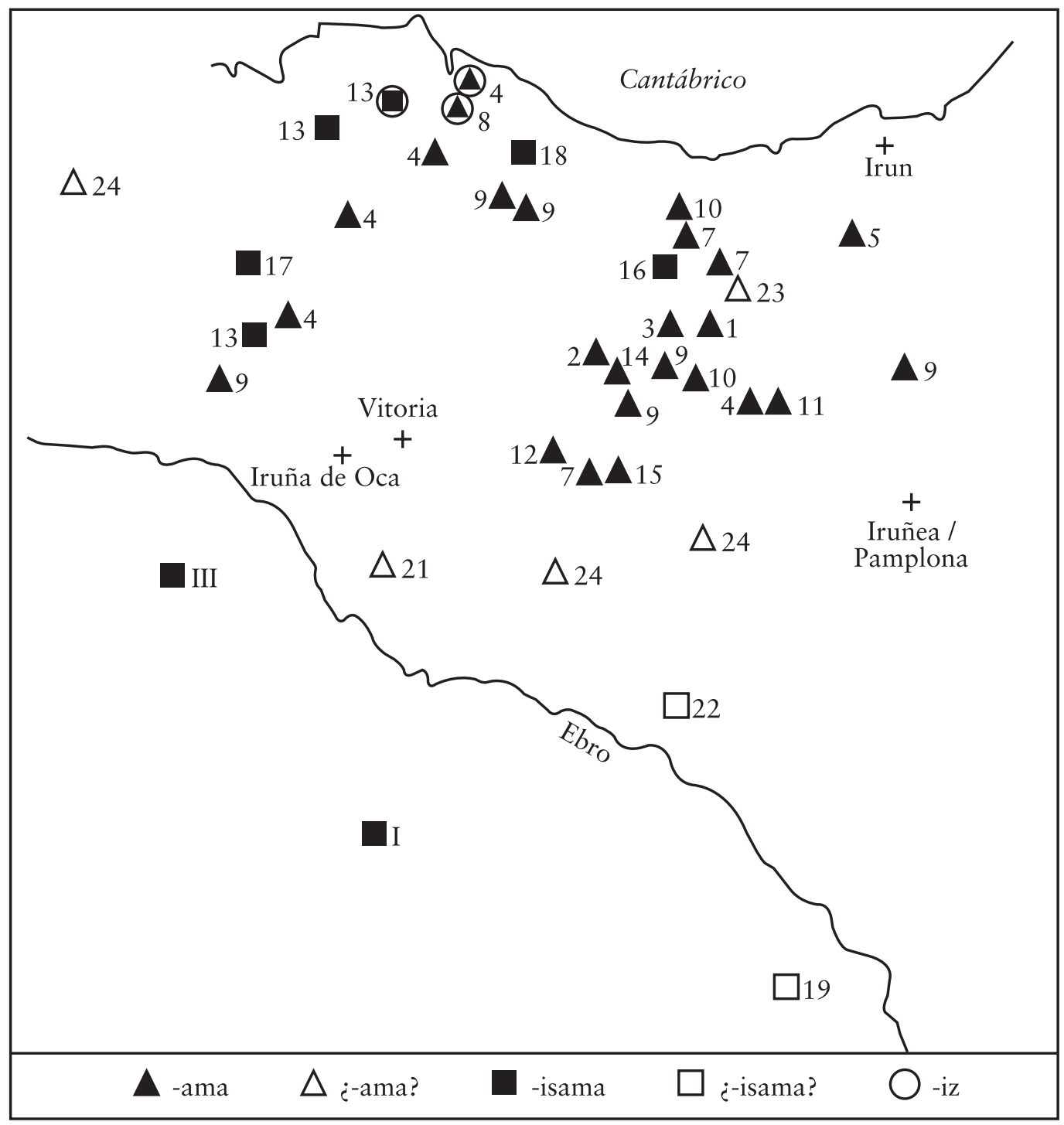

Plano 1

En opinión de Mitxelena (1977: 28), es muy posible que el territorio de los vascones, ya en los comienzos de la dominación romana, no fuese más monolingüe que la Navarra medieval y moderna, ya que su parte meridional estuvo sometida a una fuerte influencia celtibérica antes de la romanización. Para este autor (1964: 133) no es aventurado decir que de un examen de conjunto de la toponimia vasca no se llega a resultados que se opongan a la hipótesis de una penetración lingüística indoeuropea (incluso intensa), que llegó hasta lo que luego han sido zonas centrales de Vasconia. En dos palabras, en su opinión (1978: 435) el elemento indoeuropeo pre-latino parece haberse superpuesto a otro u otros anteriores y no descarta, tampoco, fenómenos de contacto con el euskera. 
Según Gorrochategui (2009: 73-74), si se toma en consideración el material onomástico de época imperial transmitido en lápidas latinas, se puede dividir el solar vascón tradicional en varias zonas diferenciadas. En la zona de la actual provincia de Álava, más un área del sector más occidental de Navarra (correspondiente a una parte de lo que se llama 'Tierra Estella'), hay una abundancia de nombres indígenas, la mayoría de los cuales pueden clasificarse lingüísticamente como celtas. La onomástica personal céltica de Álava, por su cantidad y coherente distribución territorial, es, a su modo de ver, un reflejo inequívoco de la profunda influencia céltica que sufrió el territorio a partir de zonas vecinas meridionales y occidentales.

Concretando más, Gorrochategui (2015: 18) sintetiza la situación lingüística de Álava en la antigüedad de la siguiente forma: Rioja formaba parte del territorio berón (de lengua celtibérica), los valles más occidentales eran de la etnia de los autrigones (de lengua celtibérica ${ }^{55}$ ) y en la llanada alavesa, territorio de los caristios y várdulos, los nombres de persona indicarían que la presencia celta era dominante, sin que se pueda excluir la presencia de hablantes de lengua vascona. Piensa el profesor guipuzcoano (2009: 74) que esa onomástica personal pudo ser transferida a los vecinos caristios, várdulos y vascones.

En dos palabras, a juicio de este autor (2009: 74-75) los materiales onomásticos de época imperial transmitido en lápidas latinas, los topónimos citados por las fuentes antiguas, junto con las denominaciones de algunos ríos y varios nombres de lugar terminados en -ama, apuntan a la presencia de una lengua céltica en la zona occidental del País Vasco.

3.3. Mitxelena (1982: 304) no duda de que el nombre del río Deba (que se repite más al oeste en la costa cantábrica) es una denominación céltica, pero en el tramo guipuzcoano de la cuenca de dicho río no se conocen topónimos con la terminación -ama. Cabe recordar, por otra parte, que el propio Mitxelena (1964: 126) subraya que faltan completamente en Gipuzkoa inscripciones de época romana con testimonios de antroponimia con aire indoeuropeo coincidente con la onomástica de zonas centrales de la península (Ablonius, Ambatus / Ambata, Betunus, Boutia, Buturra, Calaetus, Doitena, Equesus, Viriatus...). Como detallan Gorrochategui y De Bernardo (2001-2002: 10), la única inscripción antigua de Gipuzkoa es la de Andrearriaga (Oiartzun), en la que se lee Val(erius) Beltesonis, cuyo segundo elemento es un nombre indígena de tipo vascón. La situación de Gipuzkoa (y Bizkaia) se caracteriza, por lo tanto, por el escaso número de inscripciones y la falta casi total de onomástica indígena, en contraste con otros territorios más romanizados, como algunas zonas de Álava y Navarra.

A modo de ver de Agud (1973: 40, 46), la existencia de algunos sufijos en zonas a veces muy determinadas indicaría asentamientos que pudieron ser anteriores a los vascos o en convivencia con la lengua de estos. Así, el hecho de encontrarse los nombres 
más significativos con -ama en el centro de Gipuzkoa sería indicio de una penetración de pueblos acaso célticos. A su parecer, no puede admitirse como casual el grupo de nombres en -ama de Gipuzkoa en un área próxima al "castro» de Aldaba ${ }^{56}$ (Tolosa). Dicho "castro", con Deba y el grupo de topónimos en -ama, le hacen pensar que desde Roncesvalles hacia el Sur y Oeste la inmigración céltica pudo afectar a Gipuzkoa ${ }^{57}$ (aunque no se impusiese del todo como en el resto del Norte). En síntesis, la existencia del "castro" de Aldaba en las proximidades de To1osa le permite aventurar que los asentamientos célticos en Gipuzkoa son una realidad y que -ama es un recuerdo de ellos, como lo es Deba en la costa.

En Gipuzkoa se han descubierto varios poblados fortificados de la Edad de Hierro durante los últimos años. Hasta hoy son nueve en total los enclaves localizados: Buruntza (Andoain), Basagain (Anoeta), Intxur (Albiztur-Tolosa) y Murumendi (Beasain) en el valle del Oria; Munoaundi (Azpeitia-Azkoitia) y Belaku (Beizama) en el del Urola; Moru (Elgoibar) y Murugain (Arrasate-Aretxabaleta-Aramaio) en el del Deba, y Akutu (Bidania-Goiatz-Errezil) en las proximidades del macizo del Hernio, en la divisoria Urola-Oria. Peñalver y San José (2003: 98) concretan que, si bien existen algunas evidencias que indican que los recintos fortificados de Gipuzkoa fueron ocupados en algunos casos en la primera mitad del milenio anterior a nuestra era, la mayoría de los testimonios conducen hacia fechas más recientes: la mayor parte de los yacimientos excavados son de la segunda mitad del milenio, hasta fechas cercanas al cambio de era.

Es probable que sigan apareciendo más poblados fortificados, tanto en Gipuzkoa como en el resto de Vasconia, pero centrando la mirada en la provincia, salta a la vista que hasta hoy el inventario ha aumentado considerablemente desde que Agud relacionó los «castros» o enclaves fortificados con los topónimos en -ama, por lo que su planteamiento ha de ser revisado, más allá del supuesto carácter céltico o no de los mismos. Los mapas, por otra parte, no indican que la penetración celta se produjese a través del paso de Roncesvalles, por muy sugerente que sea dicha posibilidad.

Efectivamente, algunos de los topónimos en -ama se sitúan en lugares más o menos próximos a los recintos fortificados de la Edad de Hierro (Beizama-Belaku [1,1 km]; Ezama (Errezil)-Akutu [2,6 km]; Ezama (Tolosa)-Basagain [2,6 km]; Arama-Murumendi [4,4 km]; Ezama (Errezil)-Intxur [5,5 km]), pero no todos los lugares de esa época tienen sitios con la terminación -ama en sus aledaños (Munoandi, Moru...), ni tampoco todos los topónimos en -ama tienen un poblado fortificado en sus cercanías (Untzama, Bedama, Arakama...). Ahora bien, no se puede negar que la mayoría de enclaves fortificados en Gipuzkoa se ubican entre las cuencas de los ríos Oria y Urola (Buruntza, Basagain, Intxur, Murumendi, Munoaundi, Akutu, Belaku), lo mismo que

56 Se refiere a Intxur (Albiztur-Tolosa).

57 Cita, asimismo, que Zegama toca ya el punto mas avanzado de penetraci6n latina por el sur (Araia y Albéniz). 
muchos de los topónimos en -ama ${ }^{58}$ (Beizama, Bedama, Ezama [2], Arama, Amiama, Bedama, Untzama, Zegama, Arakama).

Por otro lado, entre otros datos, Gorrochategui (2015: 9-13) recopila y ubica en un mapa la antroponimia indígena de Vasconia atestiguada en los epígrafes, entre la que destacan los nombres indoeuropeos (célticos) de persona atestiguados tanto de Álava y Navarra. Merecen especial atención Arai (gen.) (Ilarduia, Contrasta, A), Araica (Contrasta, A; Larraona, NA) y Araca (Eslava, NA), por su probable relación con Arama y Arakama, es decir, porque sugieren que los antropónimos de Álava y Navarra no eran extraños en Gipuzkoa. Cabe mencionar igualmente Segilus (Laguardia, A), Segontius (Gauna, Okariz, Eguilaz, Salvatierra, A; Gastiáin [3], NA) y Segontiecus (Okariz, A) / Segontieca (Olazagutia, NA), debido a que su raíz está presente seguramente en el topónimo guipuzcoano Zegama.

3.4. Vista su distribución en Vasconia, conviene observar la disposición de los topónimos en -ama en los territorios contiguos, especialmente hacia el sur-suroeste, en la zona conocida como Celtiberia, desde la que pudo llegar la influencia indoeuropea (céltica). Para empezar, cabe mencionar Ledesma de la Cogolla (NGBE, LO [[ $\left.{ }^{59}\right]$ ) y Ledesma de Soria (Gomara [II]), entre otras razones porque el primero se documenta como Letesma (UPV-Galicano) al comienzo de la Baja Edad Media (1014, 1082). Sin abandonar Castilla y León, están Lucesma (paraje ${ }^{60}$; NGBE, Vallarta de Bureba, BU [III]) y Lerma ${ }^{61}$ (1079; BU [IV], UPV-Galicano), así como el conocido Burgo de Osma (SO [V]). En Aragón, entre otros topónimos ${ }^{62}$, se localiza Luesma ${ }^{63}$ (Campo de Daroca, ZAR [VI]) y, acaso, también, La Ciesma (paraje; NGBE, Grisel, Zaragoza [VII]). Sin salir de la Celtiberia, pero más lejos de Vasconia, está Eresma ${ }^{64}$ (río, corredor; NGBE, SegoviaValladolid [VIII]). En Segovia, de manera análoga, existe constancia del apellido Lesma.

Fuera de la Celtiberia, por el Este, en concreto en Huesca, llama la atención Lozama (barranco; NGBE, Larués, Bailo [IX]), primero por su ubicación (muy cerca del límite oriental de la Vasconia ibérica y bastante lejos, por lo tanto, de la mayoría de las otras muestras de -ama) en una zona en que la lengua de los vascones no fue completamente

58 Al hilo de los restos arqueológicos de finales de la Edad de Bronce-Edad de Hierro en Gipuzkoa, llama la atención que en la zona de la provincia en la que se han localizado crómlechs pirenaicos (cerca de 140) no haya topónimos con la terminación - ama; el más próximo sería Bedama, a unos 3,5 km del cromlech pirenáico de Pikuetaondarra. Este vacío es extensible a toda la zona de Vasconia donde se han localizado hasta la fecha la mayoría de estructuras circulares de la Edad de los Metales; la única excepción clara es Elama. El crómlech de Mendiluze en Entzia podría ser la segunda excepción, puesto que se ubica a 5-6 km de Zezama, pero esa estructura es excepcional dentro del conjunto de Vasconia, no solo por su situación lejos del eje pirenaico, sino también por sus peculiaridades constructivas.

59 Numeración con la que aparece el topónimo en los planos n. ${ }^{\circ} 1$ y/o n. ${ }^{\circ} 2$.

60 Ladera orientada al norte cerca del casco urbano.

61 Cfr. Lermilla (Merindad de Rio Ubierna Burgos).

62 Hay también Sisamón (Zaragoza).

63 Documentado como Luexma (1373; lugar; Crespo (1998: 110) y Lueixma (Pascual de, 1466; ibid.: 115). Muy cerca, en Vistabella de Huerba (Zaragoza), está el arroyo Carraluesma.

64 Hornillos de Eresma (Valladolid) - Yanguas de Eresma (Segovia). 
extraña y, segundo, porque puede compararse con Luesma, ya que el nombre oscense podría mostrar una evolución según las reglas del euskera $\left(-s^{-}>-z-\right)$ y el zaragozano según la reglas de las lenguas romances (-o- [breve] tónica $\left.>-u e-;-s^{-}>-s-\right)$, si bien, la no apertura de lo que parece una antigua vocal tónica breve no es un fenómeno documentado exclusivamente en ámbito vascónico. En Aragón ${ }^{65}$, pero no tan cerca de Vasconia, se ubican también Valderesma (paraje; NGBE, Casbas, Huesca), Monesma y Cajigar (Huesca), Monesma (cerro; NGBE, Abiego, Huesca) y Valdeliesma (barranco; NGBE, Mequinenza, Huesca). Llama la atención, de manera similar, Hoya Lesma en el sur de la península ibérica (paraje; NGBE, Carabaca de la Cruz, Murcia). Hacia el oeste de Vasconia (fuera de la Celtiberia) es preciso recordar, en primer lugar, el (mencionado) topónimo Arama (playa; NGBE, Pechón, SAN [X]). Más lejos, existen Cabeza Ledesma (montaña; NGBE, Ruenes, Asturias ${ }^{66}$ ) y Valdeledesma (paraje; NGBE, Alfaraz de Sayago, Zamora).

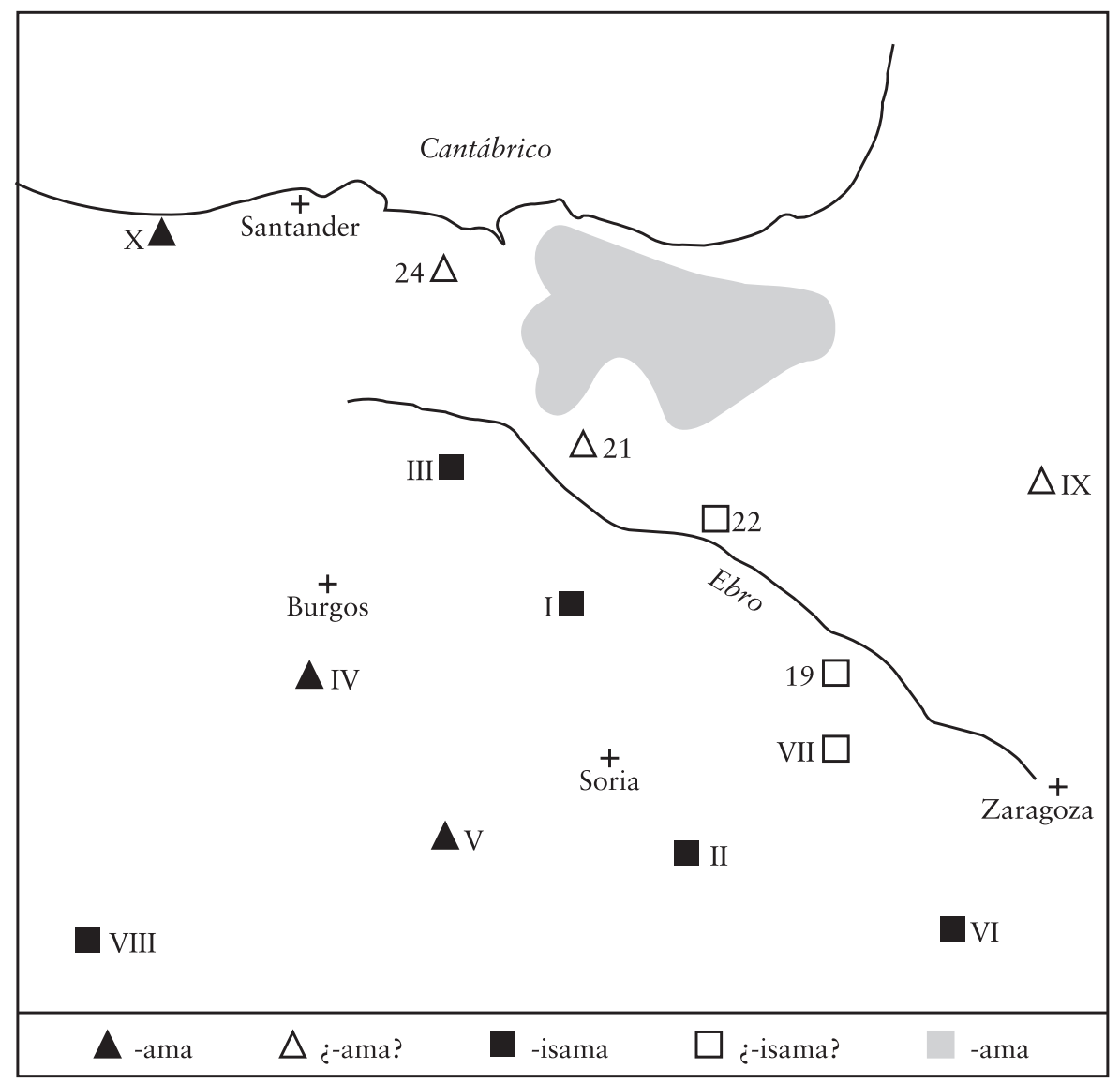

Plano 2 
3.5. Varios nombres con -ama se repiten en Vasconia (Lezama, Aldama...), en algunos casos en ubicaciones bastante próximas (Ezama, Ultzama...) y en otros no tanto (Aldama...), hecho, por cierto, bastante frecuente en toponimia. La repetición de designaciones puede deberse a varias razones. Puede ser inconsciente, es decir, puede haber existido poligénesis, pero no necesariamente. De hecho, importar e integrar nombres foráneos (en algunos casos lejanos) es un procedimiento habitual en el ámbito de la toponomástica.

A veces, puede ser un mero traslado toponímico, es decir, el lugar de procedencia (municipio, casa) puede dar nombre a otro emplazamiento al que se ha trasladado una persona o una familia. Otras veces, el origen de los topónimos que se repiten, especialmente cuando están en lugares distantes entre sí, tiene que ver, simplemente, con el deseo de emplear una denominación que en nada se parece al resto de los nombres de determinado entorno. A tal fin, un sistema bastante fecundo es importar nombres exóticos, muchas veces sujetos a modas onomásticas, aunque entre las razones de la introducción de nombres lejanos puede estar también la colonización o la presencia de extranjeros. La repetición de topónimos lejanos a propósito puede deberse, finalmente, a que el sitio a donde se ha importado y el de origen compartan características similares, es decir, puede producirse debido a un fenómeno de natonomasia. En suma, en el caso de los topónimos terminados en -ama que se repiten en Vasconia, entre otros factores, hay que tener en cuenta si aparecen también fuera de dicho territorio, especialmente en la Celtiberia.

Comenzando, por el (como diría Mitxelena) «ubicuo» Ultzama / Untzama / Osma, es necesario recordar que tiene, por lo menos, seis representantes en Vasconia, tal y como se ha dicho anteriormente, varios de ellos bastante próximos entre sí (Ataun-Parzonería General de Gipuzkoa y Álava) y, aunque en algunos ejemplos pueda pensarse en poligénesis, en el caso de Osma de Mallabia parece que se trata de un traslado toponímico, bien de Álava, bien de Soria. Tampoco puede descartarse que la proliferación de $\mathrm{Ul}$ tzama / Untzama responda a una antigua moda toponímica. En Lezama (A, BI) (esté relacionado con Ledesma, esté relacionado con Lesma) puede haber habido poligénesis y, por otra parte, es difícil que en Aldama y Ezama, por ejemplo, haya habido traslado toponímico, por lo menos desde la Celtiberia, puesto que ambos dos no se documentan fuera de Vasconia.

3.6. Reviste su interés comparar cómo se distribuyen los sufijos latinos presentes en los topónimos de origen deantroponímico (analizados y clasificados detalladamente por Salaberri) y los topónimos con la terminación -ama.

En Álava -anu / -au, -ano / -ao, - ana / - a es el grupo de sufijos más empleado en la formación de nombres de localidades (Salaberri 2015: 37-38) y es, precisamente, en ese territorio de Vasconia donde más abundantes son los topónimos que los portan. Sin embargo, en el área que circunda Vitoria -donde son frecuentes los citados deantropónimos- hay un notorio vacío de topónimos en -ama; la ciudad foco de 
-anu / -au, -ano / -ao, -ana / -a es el centro de una zona en blanco de -ama en los mapas $^{67}$.

Algo parecido sucede también, en parte por lo menos, con -ain y -ama. Salaberri (2000: 113-115) concreta que encontramos -ain sobre todo en nombres de población de la parte central de Navarra ${ }^{68}$; hay, además, algunos topónimos mayores en Zuberoa (Vasconia continental ${ }^{69}$ ), Gipuzkoa y la parte oriental de Álava ${ }^{70}$. A pesar de que en las zonas periféricas de -ain en la Vasconia ibérica (Gipuzkoa y Álava) hay topónimos en - ama, no hay ningún testimonio de -ama en la zona nuclear del sufijo de origen latino, o, dicho de otra manera, en el perímetro de Pamplona, en la zona donde más prolifera -ain, no hay testimonios de -ama.

Salaberri (2011b: 167, 169) demuestra, asimismo, que la mayoría (o todos) los antropónimos que están en la base de los nombres de lugar en - Vka son de época romana $\mathrm{y}$, en concreto, que el sufijo -ika (con moción de genero femenino) es de origen latino. Para el profesor de Ujué corresponde a los historiadores examinar qué relación tiene este hecho con la romanización de la parte occidental de Vasconia ${ }^{71}$, y a los onomastas poner en relación el empleo de $-i k a^{72}$ con otros sufijos como -ain, con el que parece estar en distribución complementaria, y con -anu / -au, -ano / -ao, de extensión más amplia (al sur de los Pirineos al menos). En ese sentido, a diferencia de lo que sucede, por ejemplo, con el sufijo -ain en Navarra, los topónimos con el sufijo de origen latino procedentes del adjetival -ica y los terminados en -ama comparten territorio en la zona nuclear del primero.

Nadie ha estudiado en profundidad los nombres de los pueblos de Gipuzkoa en su conjunto, ni tampoco los topónimos con bases antroponímicas, pero, afortunadamente, además del conocido Lazkao (< Lazcano), gracias a Salaberri se pueden identificar definitivamente como topónimos mayores de origen deantroponímico, cuando menos, los siguientes: Andoain ${ }^{73}$ (Salaberri, 2000: 114), Arroa (< Arrona; barrio Zestoa; Salaberri,

67 Sucede lo mismo con el entorno inmediato de la antigua Oiarso; la excepción sería Elama.

68 Las localidades extremas, dentro de Navarra, son las siguientes: Santsoain en Orba y Urraúl Bajo, Adoain en Urraúl Alto, Muniain en el Valle de Arce, Gerendiain y Lintzaoain en el Valle de Erro, Urritzola-Galain y Gerendiain en Ultzama, Urdiain en Burunda, Gastiain en Lana y Muniain en La Solana, sin olvidarnos de los barrios Frain de Igantzi y Lesaka, y Zalain de esta última localidad y Bera; (ibid.).

69 Domintxaine, Garindaine, Gotaine, Ozeraine y Ündüreine; (ibid.).

70 Agurain (Salvatierra), Andoin, Munain y Urabain; (ibid.).

71 El navarro Zabaldika sería el testimonio más oriental -demasiado oriental quizás en su opinión- de -ika, si es eso lo que en dicho topónimo hay y no engañan las apariencias. No hay topónimos con la terminación - ama en esa zona. También hay Lesaka en Cinco Villas de Navarra, todavía sin explicar (ibid.). Por lo que se refiere a Zúñiga, topónimo deantroponímico, está cerca de la muga de Álava y del valle navarro de Lana (Zúñiga se ubica entre Zalama de Allín y Zalama de Campezo).

72 No cree que las casas que tienen -ika sean (todas) de época romana, pero puede que hayan sido construidas sobre otras anteriores más antiguas, o, alternativamente, en lugares que tenían el nombre en cuestión.

73 Cfr. Gorrochategui (1984: 139). 
2013b: 213), Beasain (Salaberri, 2000: 114), Bedoña (barrio de Arrasate; Salaberri, 2012b: 339), Zestoa (< Cestona; Salaberri, 2013b: 213), Gabiria (Salaberri, 2011b: 163), Oikia (< Oiquina; barrio, Zumaia; Salaberri, 2012b: 346), Orendain (Salaberri, 2000: 114) y Zerain (Salaberri, 2000: 114; Salaberri, 2011b: 147). Si se compara la distribución de esos topónimos mayores con sufijos latinos y los que tienen -ama, se observa que en la zona de mayor densidad de esa última terminación no faltan los deantropónimos romanos. Ahora bien, llama la atención, por ejemplo, que en una zona con numerosos topónimos con bases y sufijos latinos como la cuenca del río Deba ${ }^{74}$ no haya nombres con la terminación -ama.

Con todo, en Bizkaia (-VKa), sur de Gipuzkoa (-ain, -ano, -ona) y norte de Álava (-ain, -ano, -ana) los topónimos con sufijos latinos y con la terminación -ama comparten el mismo territorio, situación que no se repite en las zonas circundantes a Vitoria y Pamplona, epicentro de los sufijos - ana, -ano o -ain. Se observan, por lo tanto, sendas áreas toponímicas en torno a las ciudades de Pamplona y Vitoria (¿Iruña de Oca?) con un claro vacío de -ama.

Gorrochategui (1993: 125) se pregunta si es imaginable pensar que en la Antigüedad en toda Vasconia se hablaba una lengua vascona relativamente uniforme, o, por el contrario, el dominio se hallaba fuertemente dialectalizado, de manera que los actuales dialectos serían la continuación de esos hipotéticos dialectos antiguos. Opina que a esta pregunta ya respondió Mitxelena de alguna manera al afirmar que los dialectos vascos históricos no presentan unas diferencias muy grandes y, por consiguiente, la fase de unidad no debe remontar a una gran antigüedad. Si se atiende a las áreas toponímicas que dibujan algunos de los principales sufijos de origen latino empleados junto a bases antroponímicas para crear topónimos que indican posesión (-ain, -ana, -ano y -Vka) la respuesta a la pregunta de Gorrochategui no parece tan evidente, y tampoco la topoglosa de -ama aporta mucho, precisamente, a la imagen de homogeneidad lingüística de Vasconia en la Antigüedad.

\section{ESTRATO LINGÜÍSTICO}

4.1. Además de arriesgado, es ciertamente complicado extraer conclusiones de orden cronológico de un corpus toponímico tan reducido, sean de orden interno, sean de orden externo, máxime cuando se trata de probables elementos procedentes de lenguas

74 Sirvan como ejemplo los que tienen el sufijo latino -ao (<-ano): Amatiño (Amatiano, 1857; casa de labor; Bergara), Andikao (Andicano, 1857; casa de labor; Elgoibar), Arginao (Arguiano, 1437; Arguináo, 1857; casa de labor; Eibar), Berezao (Berezano; paraje; Oñati), Birinao (Birináo, 1857; casa de labor; Eibar), Buruñao (Burunano, 1450; Burinano, 1598; barrio, casa de labor; Bergara), Ekutio (Ecutyano, 1448; Ecutio, 1857; casa de labor; Arrasate), Garitao (Garitano, 1857; barrio, casa de labor; Bergara), Gellao (Guellano, 1857; barrio, casa de labor; Eskoriatza), Gomistio (Gomistiano, 1476; Gomistio, 1857; casa de labor; Arrasate), Karkizao (Carquisano, 1857; casa de labor; Eibar) / Karkizao (Carquizano, 1857; casa de labor; Elgoibar), Lamariño (Lamariano, 1514, 1857; casa de labor; Antzuola), Lutxurdio (Luzurdiano, 1857; casa de labor; Bergara), Marindao (Marindaño, 1554; Marindano, 1563; barrio; Bergara), Olandio (Olandianno, 1476; Olandiano, 1857; casa de labor; Arrasate). Cfr. Salaberri (2013a). 
desaparecidas, atestiguadas fragmentadamente y que no han sido descifradas completamente a día de hoy. Tampoco hay que olvidar que la onomástica es una fuente de información indirecta, complementaria en suma.

Aun así, no está completamente fuera de lugar intentar determinar en qué momento se produjo el hipotético contacto y cómo se materializó, esto es, en qué contexto llegó al ámbito vascónico septentrional la influencia indoeuropea pre-latina en general y la terminación -ama en particular, y durante cuánto tiempo se prolongó allí su presencia.

Prósper (2005: 278-282) sostiene que no se ha estudiado satisfactoriamente todavía la relación entre los sufijos de superlativo de la zona celtibérica propiamente dicha y los del área hispano-celta lateral, fundamentalmente procedentes de la mitad occidental de la península ibérica. Observa que en esta última zona se encuentra un tipo que apenas conoce paralelos en la Celtiberia, el tipo simple *amo, documentado sólo en antroponimia y toponimia. A pesar de omitirlo, el tipo simple al que se refiere Prósper está presente en Vasconia y -ama, su doblete femenino, como se ha visto, tampoco es desconocido.

Partiendo de la premisa de que la mayoría de los superlativos en -amo documentados en la península ibérica sería de distribución netamente marginal respecto a la Celtiberia, Prósper (2005: 278-282) formula la hipótesis de que en la Celtiberia central se habrían eliminado en algún momento prácticamente todos los casos de sufijación en *amo, que en fecha más primitiva alternaban con una serie de sufijos isofuncionales de mayor complejidad morfológica como *-tamo e *-(i)samo, y se habrían sustituido sistemáticamente por formas en "-(i)samo-. En opinión de dicha autora, en los márgenes de Hispania la sufijación en *-amo- no solo se conservó, sino que conoció algún destello aislado de productividad analógica. Desafortunadamente, no concreta si su propuesta incluye también a Vasconia. Para Prósper (ibid.) solo en ciertos casos se observa que la toponimia en *-isamo- se extiende por toda Hispania sin que, por lo demás, se le conozca un correlato simple en *-amo; sería el caso de *(p)letáisama > Ledesma (SO, LO, Salamanca) o *Segísamal -o > Sasamón (BU), Sésamo (LE), Sésamo y Sísamo (ACO). Esto se debería con toda probabilidad, en su opinión, a que las lenguas celtas nunca conocieron más que esa protoforma ("*-[i]samo) con exclusión, por tanto, de hipotéticos casos como "*seg-amo o $*$ *let-amo.

En primer lugar, sin ser tan abundantes como los que tienen -ama, existen en Vasconia varios topónimos en -isama y también en -isamo. Por otro lado, Zegama parece un correlato simple de Segisama, de manera que, de ser válida la hipótesis de Prosper para Vasconia, el topónimo del Goierri guipuzcoano no sería específicamente de origen celtibérico, sino seguramente anterior, por así decirlo, de origen genéricamente indoeuropeo. En definitiva, aplicando la hipótesis de Prósper, en Vasconia (a diferencia de la Celtiberia central) coexistirían topónimos «indoeuropeos» a secas y celtibéricos, estos últimos más recientes y menos abundantes. Con todo, siendo 
como es communis opinio que la terminación -isama es más moderna que -ama ${ }^{75}$, cabe pensar que los topónimos estudiados en este artículo responden a dos estratos lingüísticos diferentes.

4.2. Los préstamos del latín, en la medida en que sus formas iniciales o de partida son conocidas y pueden ser adscritas a unas fechas aproximadas, permiten, siquiera en parte, reconstruir la prehistoria de los sonidos vascos. De la Hoz y Mitxelena (1974: 186-187) señalan en ese sentido que han de tenerse en cuenta dos aspectos, contradictorios a primera vista: los préstamos serán tanto más antiguos cuanto mejor conserven su aspecto original, en la medida en que no muestren señales de los cambios fonéticos que se han realizado en los romances vecinos y, a su vez, serán tanto más antiguos cuanto más hayan modificado su aspecto original, en la medida en que hayan participado de otros, propios del vasco mismo, ya que esta participación es la mejor prueba de que se habían incorporado al léxico de la lengua antes de su cumplimiento.

Para Gorrochategui (2000: 105) el tratamiento lingüístico que sufren los topónimos latinos del País Vasco, incompatible con el romance y congruente con el euskera, confirma que los hablantes indígenas de esa región eran vascos ${ }^{76}$. Tiene su sentido contrastar, por lo tanto, el tratamiento lingüístico de los topónimos en -ama que han evolucionado según las reglas de la lengua vasca con el que han tenido los que lo han hecho según las reglas del romance, y comparar los cambios y diferencias identificadas en ambos casos con el comportamiento lingüístico que han tenido los topónimos de origen latino en Vasconia.

El siguiente cuadro recoge topónimos de origen indoeuropeo pre-latino ubicados en Vasconia, Celtiberia y el resto de la península ibérica que han podido evolucionar según las reglas del euskera y según las del romance.

Cuadro ${ }^{\circ} 1$

\begin{tabular}{|l|l|l|l|}
\hline Vasconia (eusk.) & Vasc. (rom.) & Celtiberia & Resto península \\
\hline Lezama, Legizama & & Ledesma, Lesma & Lesma, Valdeliesma \\
\hline & & Luesma & Lozama \\
\hline Ultzama, Ozama & Osma & Burgo de Osma & \\
\hline Erama & & Eresma & Valderesma \\
\hline
\end{tabular}

75 Entre los autores que admiten que -isama / isamo es posterior a -ama / -amo se encuentran Joaquín Gorrochategui (comunicación personal) o el propio Villar (2005b: 483).

76 Cfr. Salaberri (2010: 221). 
Mitxelena (1972b: 334) afirma que algunos nombres de tradición éuscara dan testimonio de un estado de cosas en que $i$ breve no se había confundido todavía en cuanto al timbre con -e- larga; de forma análoga, frente a Ledesma $(<$ Letisama) y Eresma $\left(<*\right.$ *[p]er[a]isama) en castellano, hay Legizama en lengua vasca ${ }^{77}$.

Un cambio significativo entre los topónimos con -ama de influencia latina es la síncopa de la - $a$ - postónica, a pesar de que, como subraya Mitxelena (1960: 247-248), se conserve habitualmente en los romances españoles, y, por ejemplo, Osma no haya salido regularmente de Uxama. Prósper (2005: 283) piensa, por un lado, que en el caso del sufijo complejo "-isamo- ( $>$ "ismo-) podría haber habido en época pre-latina una tendencia general a la síncopa ("isamo- $>$ *-ísmo-) y, de la misma forma (2004: 186-189), considera que Uxama (< "samo-) estaría entre los topónimos hispanos de origen celtibérico con acento en la antepenúltima pero supuestamente sin síncopa hasta época romance. En dos palabras, la síncopa se habría producido en diferentes épocas en ambos casos (en -ísamo y -samo): Letesma (1014, 1072; < Letisama) vs. Oxoma (c. 1239 ; < Uxama). Visto que en Vasconia hay varios topónimos terminados en -izama / -izamo, parece claro que cuando se produjo la síncopa -ísamo >-ismo en la Celtiberia en vasco la penúltima sílaba no era átona. En ese sentido, recordar que Salaberri (2015: 410), en su libro sobre los nombres de los pueblos de Álava, constata que las síncopas son raras, tanto entre los topónimos de origen vasco como en los de origen latino ${ }^{78}$.

Por otra parte, en los topónimos en -ama que han evolucionado según las normas del euskera aparece la sibilante dorsal, mientras que en los que se atienen a las leyes romances hay una apical, fenómeno que se repite en los préstamos latinos de influencia vasca más antiguos. Así, Salaberri (2015: 419) pone el céltico Lezama como ejemplo de $-z$ - procedente de $-s$ - en interior de palabra.

Para terminar con la comparación de los cambios producidos por influencia del euskera en los deantrotopónimos con sufijos latinos según los clasifica Salaberri (2015: 408411 416-418) con los cambios identificables en los topónimos con la terminación -ama, se observa que, si en los préstamos latinos de evolución romance las oclusivas sordas sonorizan en posición intervocálica (o entre vocal y vibrante) (Arbígano), sin embargo, en los de influencia vasca no sonorizan en dicha posición (Apodaka), lo mismo que, por ejemplo, en Arakama ${ }^{79}$. De igual forma, a diferencia de la tradición romance, las

77 En otros topónimos de posible influencia vasca como Lozama no se observa ningún caso posible de diptongación comparable a la producida en las formas romances (cfr. Luesma) que han podido evolucionar a partir de la vocal breve latina -o-.

78 Una de las excepciones más conocidas es Hermua (Barrundia, A), donde la -e- interior ha caído a causa del acento heredado del modelo latino; $c f r$. lat. éremus > eus. eremu ('desierto', 'extensión', 'término') vs. cast. yermo (op. cit., 213).

79 Cfr., por ejemplo, Letesma (1076) > Ledesma (de la Cogolla, LO). 
oclusivas sordas sonorizan tras nasal y lateral en euskera (cfr. Alda; *Antana > Anda y Andagoia), cambio probablemente presente también en Aldama.

4.3. En el cuadro n..$^{\circ}$ se muestran juntos topónimos terminados en -ama, nombres de lugar de origen pre-latino de la península ibérica y posibles raíces indoeuropeas.

Cuadro n. ${ }^{\circ} 2$

\begin{tabular}{|c|c|c|}
\hline Topónimo & Nombre de origen pre-latino & Posible raíz indoeuropea \\
\hline Bedama (2) & $\begin{array}{l}\text { Medamus }{ }^{80} \text { (Vizela, Portugal) } \\
\text { Bedam }\end{array}$ & $\begin{array}{l}\text { "medh- }{ }^{81} \\
\text { "bed- }(>\text { "bedo- })\end{array}$ \\
\hline Berama & Beresmo $<$ BERISAMO & $\begin{array}{l}\text { "uer- ( > *uer[o]-) } \\
\text { "wer- } \\
\text { "bhel- } 82\end{array}$ \\
\hline Zegama & $\begin{array}{l}\text { Sasamón < Segisamo, Segisama } \\
\text { Ejea de los Caballeros < Segia }\end{array}$ & $\begin{array}{l}\text { "segh- ('coger, tener') } \\
\text { ( > "sego-, 'victoria') }\end{array}$ \\
\hline Lezama (2) & $\begin{array}{l}\text { Ledesma }<(\boldsymbol{P}) \text { letisama } \\
\text { Lesma }\end{array}$ & $\begin{array}{l}\text { "pleth- } \\
\text { "less }{ }^{83}-(>\text { Lesso, less })\end{array}$ \\
\hline
\end{tabular}

Llama la atención el número de topónimos de Vasconia en -ama que tienen posibles raíces con una vocal como núcleo y que terminan y comienzan con una consonante $(C V C)$, estructura que, a primera vista, curiosamente, coincide en lo básico con la forma canónica propuesta por Mitxelena y Lakarra para las raíces monosilábicas del protovasco (vid. Lakarra, 2011). Sin embargo, si se presta un poco de atención se observa que la vocal es siempre /e/ y las consonantes (excepto en Zezama, $i<{ }^{*}$ Cesama?) no se repiten en la misma raíz, rasgos característicos de la forma canónica de las antiguas raíces indoeuropeas según la concreta Benveniste ${ }^{84}$ (1935-150-171). Cabe añadir al cuadro $n^{\circ} 2$ los topónimos de Vasconia Beizama (Be-), Leizama (Le-), Lexamona (Le-) y -aunque no conservan consonantes en el ataque- también Ezama, Entzama (Ez-), Elama (El-) y Erama (Er-).

Entre las posibles raíces de los topónimos de ámbito vasco que tienen como núcleo la vocal media /e/ y comienzan y terminan con una consonante, como inicial solo se observa /b/, /l/ o /z/ y como coda /g/, /d/ /l/, /r/, /z/ y /tz/, es decir, en el ataque faltan las oclusivas sordas, nasales, vibrantes y sibilantes ápico-alveolares y en posición final las

80 Cfr. MEDAMA (f.) (Cisalpina).

81 Cfr. Villar (1995: 61).

82 Cfr. Villar (2005a: 198).

83 Albertos (1966: 130) inventaría el nombre Lesso, tal vez en relación, según dicha autora, con el irl. less ('castillo, morada').

84 Cfr. López Eire (1971, 269-272) y Lakarra (2011: 11-13). 
oclusivas sordas, las nasales, la vibrante múltiple y las sibilantes ápico-alveolares, de lo que se puede inferir el siguiente esquema ${ }^{85}$ :



\section{SIGNIFICACIÓN}

5.1. La mayoría de los topónimos terminados en -ama de Vasconia no se ubican en lugares con cualidades o características extraordinarias o únicas, no están en lugares muy altos (cumbres, cimas), muy bajos (dolinas, barrancos), muy grandes (llanadas, mesetas) o muy pequeños (collados, portillos), de forma que es raro encontrar sobre el terreno argumentos que faciliten relacionarlos con adjetivos superlativos ${ }^{86}$. Este hecho tiene que ver seguramente con la propia orografía de la zona en que se localizan muchos de ellos, donde el relieve es intrincado pero bastante homogéneo y, en consecuencia, es difícil que existan accidentes que sobresalgan o destaquen sobremanera sobre el resto. La mayoría de los topónimos están en laderas (Amiama, Arakama, Aldama, Enzama [2], Untzama [Ermua], Osma [2], Bedama [2], Berama, Beizama [núcleo principal], Legizama) y varios de ellos en fondos de valle ${ }^{87}$ (Aldama, Elama, Zegama [núcleo principal], Osma [núcleo principal]). Otros están en lugares relativamente llanos y bastantes amplios ${ }^{88}$ (Zezama, Lizama; Santiama, Osma [casco]). Los únicos que estarían en lugares relativamente prominentes o sobresalientes serían ${ }^{89}$ Untzama [Ataun] (espolón), Ultzama [Parzonería] (rellano) y Arama (rellano sobre río).

85 A excepción de Arkamo (cfr. Arakama) y Zaratamo, el resto de topónimos en -amo /-isamo que se mencionan en este trabajo (Godamo, Legizamo, Beramo y Orizamo) no contradicen el paradigma. El cuadro es, de igual manera, coherente con algunos procesos fonológicos que caracterizan al celtibérico, como la perdida de la labial sorda indoeuropea " $p$ en determinados contextos (inicial absoluta y posición intervocálica) y su transformación en otras posiciones, esto es, la eliminación de * $p$ indoeuropea en el sistema fonológico de las oclusivas (Gorrochategui, 1991: 14, 15). La casilla de la oclusiva velar sorda /k/ estaría vacía, igualmente, en el último estado de evolución del celtibérico (Jordán, 2004: 67).

86 Se tienen en cuenta solo los topónimos en los que la presencia de la terminación-ama es relativamente segura. En cualquier caso, el grupo de los que son dudosos no contraviene los resultados: fondo valle (Txarama), colina (Sesma) y cumbre (Zalama).

87 A este grupo se podría añadir, tal vez, Ozamiz (orilla de la ría de Urdaibai).

88 El valle navarro de Ultzama estaría seguramente en este grupo.

89 Cfr. Beramo (monte). 
El caso de Utzama (Ultzama, Untzama), Osma es significativo. La opinión común es que Uxama significa 'la muy alta', 'la más elevada', pero, sin embargo, la mayoría de sus representantes no tienen esa particularidad, ya que, como se ha dicho, se ubican en laderas o fondos de valle.

Si se fija el foco de atención en el designatum, esto es, en las entidades geográficas denominadas por los nombres con $-a m a^{90}$, la mayoría están relacionados con la huella humana, con lugares de habitación o actividad económica. Municipios: Arama, Ultzama, Osma, Lezama, Zegama, Beizama; despoblados: Berama; barrios: Aldama, Lezama, Legizama; seles: Ultzama, Bedama (2), Laxamona; caseríos: Amiama, Arakama, Aldama, Aldamiz, Ezama (2), Ozamiz, Osma, Lezamiz; Apellidos: Erama, Leizama. Por contra, son pocos los que designan entidades geográficas que tienen que ver exclusivamente con la orografía o la hidrografía, elementos naturales asociados al medio físico o el relieve; ladera: Untzama Parzonería, GI); espolón: Untzama (Ataun, GI); raso: Zezama; paraje: Aldama (2), Entzama; regata: Elama.

5.2. Es probable que en algunos topónimos en -ama la base sea un antropónimo (Arakus, Amius) y, en consecuencia, cabe preguntarse si -al igual que en el caso de los topónimos de origen latino que indican pertenencia- en el momento de su creación no había también un nombre común (cfr. ager, fundus, terra, villa, vicus), elemento genérico que, de manera similar a los de deantropónimos romanos, habría sido elidido ${ }^{91}$, extrapolando, en suma, el paradigma de los topónimos romanos Araka (*[villa, terra...] Arakana) y Amiano ("[fundus, vicus...] Amiano) a Arakama y Amiama. Sin embargo, ese modelo subyacente en los deantropónimos parece opuesto al esquema adjetivo (alta, ancha, victoriosa) + grado superlativo (la más, la muy) de topónimos como, por ejemplo, Ultzama.

5.3. Salaberri (2015: 43) subraya que en alguna ocasión encontramos el sufijo -itu con la misma base que -ika, e incluso que -ain, como, por citar un caso, en Gorozitu ${ }^{92}$ / Gorozika (BI) / Goroziain (> Gorozin > Grozin, NA), los tres basados en el antropónimo latino Crosius. También a veces (Salaberri 2000: 126) se encuentran los sufijos -(i)(t)z y -ain con la misma base antroponímica: Beraskoitz (Beskoitze) / Beraskoain (Berasko); Urdaitz, Urdotz / Urdain, Urdiain.

De manera similar, hay algunos topónimos con sufijos de origen latino y otros con la terminación -ama que aparentan tener la misma base, o una muy similar. Comenzando con Aldama, el hecho de que en Bizkaia se documenten los caseríos Aldaica (1704, Kerexeta, 1992: 51; Arrieta) y Aldaca (3) (1704, ibid.: 146; Gerrikaitz) obliga a no descartar

90 Se consideran solo los nombres de lugar en los que es más probable que haya -ama. En el grupo de los que son dudosos hay más entidades geográficas relacionadas con la orografía; municipio: Sesma; caserío: Txarama; apellido: Harrama; cumbre: Zalama; paraje: Zalama: (2); hidrografía; Santiama.

91 Vid. Caro Baroja (1945: 93, 113) y Salaberri (2012a: 211).

92 Nombre de un barrio de Zeberio (BI) convertido en el habla popular en Gostu. 
completamente la posibilidad de que la base Alda- esté, tal vez, relacionada con un antropónimo $^{93}$. En concreto, visto que en Sofuentes (ZA) se documenta el nombre Altus Dusanharis (Castillo 2013: 74; cfr. Hesperia- BDLP, onom. 595), la base de Aldama podría ser Altus, que en ámbito vascónico daría Ald-, por sonorización de oclusiva ante lateral, como lat. altare > vasc. aldare ('altar').

En el Condado de Treviño está el pueblo Ozana (cfr. Ozamiz) que según recoge Salaberri (2015: 324) se documenta como Fozana en la Edad Media y tiene en su base un nombre de persona. Sin descartar la hipótesis de Albertos (1970: 211), quien cree que Ozana es similar al topónimo asturiano Fozana basado en Faucius o Falcius, Salaberri (ibid.) estima que otra posibilidad sería partir de *Fautius, variante de Fautus, es decir, de *(uilla) fautiana $>$ "Fotzjana (con monoptongación del diptongo -au-y asibilación del grupo $-t j-)>$ *Fotzana (con la yod absorbida por la consonante anterior) > Hozana > Ozana (con pérdida de la aspiración inicial).

Respecto a Berama, en Oláibar existe el lugar de Beraitz y en Álava López de Guereñu (1989: 113) hace tres referencias a Berana (término, Galarreta; fuente, Tuyo; labrantío, Luzuriaga). En Mallabia (Bi) se documentan, de la misma manera, los caseríos Berano barrenechea, Berano aurtena, Berano goitía y Berano aguirre en la fogueración del año 1704 (Kerexeta, 1992: 178). Teniendo en cuenta que Solin y Salomies (1994: 203) dan fe del antropónimo Verus, no es imposible, por lo tanto, que la composición de Berama ${ }^{94}$ sea, acaso, $\operatorname{Ver}(u s)+-a m a$.

En Burgos, no muy lejos del límite con Vasconia, está el pueblo Lezana de Mena (cfr. apellidos Lizana, Lizano) y en Kortezubi (Bi) el caserío Lezika (1704, Lezica goxeascoa; Kerexeta 1992: 98), dos topónimos que, viendo su final, bien podrían tener bases antroponímicas. En consecuencia, al margen de su potencial relación con Lesma, no habría que desestimar del todo la hipótesis de que Lezama sea un deantropónimo. Una posibilidad es que esté basado en Letius, Lettius (Solin y Salomies, 1994: 104), con un étimon Letius + -ama > "Letiama > "Letjama > Lezama; la otra es que, de manera similar a Lezika (< "Lesica < Lesius, vid. Salaberri, 2011b: 164), el antropónimo que está en la base sea la variante ${ }^{95}$ (no documentada) "Lesus.

Asimismo, en Elgeta (GI) existe el caserío Beizua (Beiçua, 1625; Beiza, 1857, NPG: 121; cfr. San Martin, 2000: 11) y en Loiu (Bi) otro llamado Beika (1511, Fortunno de Beyca, Enríquez et al., 1997: 295, Bilbao; 1796, Beica, casería, molino, Kerexeta, 1992:

93 Otra cosa es su relación con Aldana, bastante abundante en el occidente de Vasconia, concretamente en Bizkaia (barrio, Alonsotegi; caserío, Forua, Muxika y Barakaldo...) y probablemente relacionado con altano (< 'viento costero'; lat. altanus).

94 El antropónimo Bela se documenta en Vasconia en la Edad Media (Salaberri, 2003: 158) y el cambio VlV > $\mathrm{VrV}$ es conocido en legua vasca ("Belama $>$ ¿Berama?).

95 Cfr. Laebius / Laebus, Lanius / Lannus, Magnius / Magnus, Maianius / Maianus (Solin y Salomies, 1994: 100-101, 110-111). 
676). En A Coruña, por otra parte, el Instituto Nacional de Estadística del Gobierno español (INE) lista el apellido Beizana ${ }^{96}$. Visto lo anterior, Beizama podría ser un nombre de lugar con un antropónimo como base ${ }^{97}$, bien Veitius (relacionado con Bitius; Solin y Salomies, 1994: 200) y un étimon *[villa] Beitiana "Beitjama > Beizama, bien Beius (Solin y Salomies, 1994: 33), Ve(h)ius (Be[i]-98 + -isama; op. cit., 199), incluso Benus, Benius (op. cit., 33) o Venius (op. cit., 199), en la línea de lo que propone Salaberri (2011b: 161) para Beika.

En Belmonte de Miranda (Asturias) está, igualmente, el pueblo Cezana ${ }^{99} \mathrm{y}$, a la luz de ese ejemplo, habría que considerar la posibilidad de que la base de Zezama ${ }^{100}$ fuese un antropónimo del tipo Caetius, Cettius (Solin y Salomies, 1994: 41, 54): Ceti(us)- + ama $>$ *Cetiama $>$ *Cetjama $>$ Zezama.

Como puede verse en el cuadro n. ${ }^{\circ} 3$, las bases que, además de con la terminación -ama, podrían haberse combinado con sufijos de origen latino ${ }^{101}$, lo harían mayoritariamente con -Vka, -ana y -ano, aunque parece que también puede haber -i(t)z y -ona.

96 En Santander existe el municipio Santa Cruz de Bezana, en Burgos la entidad local menor Bezana (Valle de Valdebezana) y en León (Alija del Infantado) el despoblado La Vizana (La Puente Beizana; Rabanal 1994: 204). En ese sentido, Salaberi (2015: 382) es de la opinión de que en la base Villabezana (Villavizana, 956; Billa uizana, 1025), pueblo de Ribera Alta (A), está Bitius, que daría > *uilla bitiana, forma que, por evolución romance, se habrá convertido en Villabizana.

97 En el caso de Leizama habría que considerar, igualmente, que la base fuese un nombre de persona, como, por ejemplo Lenius (Solin y Salomies 1994: 103): "Leni- +-isama > "Lenisama > "Lenizama $>$ Leizama (cfr. Beizama).

98 Albertos (1966: 244) afirma que el radical Vei- está muy extendido fuera de la península, principalmente en la región de influencia Veneta.

99 En Labastida (A) López de Guereñu (1989: 152) documenta el prado de Cenzano (1687) y en Lagunilla del Jubera (Logroño), no muy lejos de Navarra, está la aldea (antiguo ayuntamiento) de Zenzano.

100 Solin y Salomies (1994: 75) se hacen eco del antropónimo Etius, que abre la puerta a la hipótesis de que el étimo de Entzama sea Eti(a)- + -ama > "Etiama > "Etjama > Ezama (> Entzama).

101 En el caso de Lizama, señalar que, visto que Lizana y Lizano son apellidos (con sufijos probablemente latinos) documentados en Zaragoza y Teruel (cfr. apellido Lizancos ACO), la posibilidad de que en la base del topónimo de Cintruénigo haya un antropónimo no se antoja completamente descabellada. De igual forma, de no ser originaria la /h/ inicial ( $c f r$. Entzama), cabría pensar también en una base antroponímica en Harrama, como, por ejemplo, Arrus (cfr. Arrona / Arroa [GI], Arróniz / Arroitz [NA]; Salaberri, 2011a: 247-248), si bien, teniendo en cuenta que solo se documenta una vez, puede tratarse desfiguración del topónimo Arama. Finalmente, en lo que concierne a la base de Santiama, el apelatibo santi ('santo') es común tanto en la toponimia de Vasconia (cfr. Santizabal, 1995; paraje, TCN-XXIII, 76; Eulz [Allín], NA), como en la antroponimia medieval; prueba de ello, Salaberri (2003: 164, 177, 254) lista los nombres de persona Santius (Santius Beraxaiz, 1080; Santius Enecos, 1149) y Santia (Santia Berderadiz de Çariquiegui, c. 1200), del latin sanctius (< sanctus, sanctii / -a; cfr. Santius, c. 1100, comes, Erro; Goñi Gaztambide, 1997: 101). 
Cuadro n. ${ }^{\circ} 3$

\begin{tabular}{|c|c|c|}
\hline$-a m a$ & Topónimo con sufijo de origen latino & Posible antropónimo base \\
\hline $\begin{array}{l}\text { Aldama } \\
\text { Aldamiz }\end{array}$ & Alda (A), Aldaika (BI), Aldaka (BI) & Altus, "Alta \\
\hline Ozamiz & Ozana (BU), Fozana (AS) & $\begin{array}{l}\text { Faucius } \\
\text { "Fautius }(<\text { Fautus) }\end{array}$ \\
\hline Berama & Beraiz (NA), Berano (BI), Berana (NA) & Verus \\
\hline $\begin{array}{l}\text { Lezama } \\
\text { Lezamiz }\end{array}$ & Leza (A), Lezika (BI), Lezana de Mena (BU) & "Letia, "Lecia \\
\hline Zezama & Cezana (AS) & Caetius, Cetius \\
\hline Beizama & Beizua (GI), Beika (BI), Beizana (ap. ACO) & Veitius, Beius, Ve(b)ius, Ben(i)us \\
\hline
\end{tabular}

\section{CONCLUSIONES}

6.1. Con la prudencia a la que obliga un corpus tan exiguo como el que se ha empleado en este trabajo (unas 30 muestras relativamente seguras y 8 dudosas), cabe concluir, en primer lugar, que la mayoría de los topónimos en -ama no se distribuyen de manera uniforme en toda Vasconia. Muchos se concentran en el triángulo Errezil-Entzia-Arakil, en cuyo centro está el Goierri guipuzcoano, de manera que el territorio donde son más abundantes los ejemplos de -ama es Gipuzkoa. Tal vez porque las áreas onomásticas no presuponen necesariamente áreas lingüísticas o, tal vez, por alguna otra razón, curiosamente, la distribución de los topónimos con la terminación -ama no delimita posibles focos de población de lengua indoeuropea en determinadas zonas de Álava y sur de Navarra desde las que pudo partir su empleo hacia el norte, no dan fe de que en la parte meridional de Vasconia hubiera alguna zona de lengua celtibérica donde el uso de -ama fuera más intenso (o tan intenso) que en el norte de Álava, Bizkaia, sur de Gipuzkoa y noroeste de Navarra. Lo que muestran los mapas es que la mayoría de topónimos en - ama de Vasconia se ubican en la parte montañosa, en el norte, y no en la llanada alavesa o el sector más occidental de Navarra, por citar dos zonas a priori representativas de la presencia indoeuropea pre-romana.

Sin embargo, hay que señalar que los antropónimos indígenas de Álava y Navarra (Arai [gen.], Araica, Araca, Segilus, Segontius...) no eran extraños en el sur de Gipuzkoa (cfr. Arama, Arakama, Zegama), lo que sugiere que la provincia no estaba aislada de las zonas más indoeuropeizadas de la Vasconia ibérica, sino, más bien, lo contrario. Los mapas de -ama y los de los antropónimos indoeuropeos pre-latinos apuntan a que estos últimos pudieron ser transferidos a Gipuzkoa desde el noreste de Álava. En concreto, la zona de Entzia-Salvatierra es la única en la que hay testimonios epigráficos de antropónimos indoeuropeos pre-latinos y topónimos con -ama.

Del examen conjunto de la toponimia en -ama se llega al resultado de que en determinadas zonas del norte de Álava, Bizkaia, noroeste de Navarra y, sobre todo, del sur de Gipuzkoa, hubo una influencia lingüística indoeuropea. En ese sentido, si bien es cierto 
que algunos de los topónimos en -ama de la provincia se sitúan en lugares más o menos próximos a los poblados fortificados de la Edad de Hierro, no todos los recintos de esa época tienen lugares con dicha terminación en sus aledaños, ni tampoco todos los topónimos en -ama tienen un poblado prehistórico en sus cercanías.

De la misma manera, cabe destacar que, en general, en la Celtiberia la densidad de topónimos con la terminación -ama no es mayor que en el norte de Vasconia. Ese dato, junto al hecho de que al sur de Vitoria y Pamplona, especialmente en los aledaños del Ebro (en la zona de contacto entre los dos territorios) la densidad de topónimos con la terminación -ama no varíe, es decir, sea menor que más al norte, difumina el hipotético continuum entre Vasconia y la Celtiberia. En resumen, llama la atención que en la Celtiberia, territorio central de la cultura celtibérica, no se identifique ningún foco de -ama como el que existe en el triángulo el Errezil-Entzia-Arakil (en cuyo centro está el Goierri guipuzcoano).

Algunos de los topónimos terminados en -ama se repiten, tanto en Vasconia como en otros lugares de la península ibérica. Puede haber ejemplos de poligénesis, pero parece que hay también traslados toponímicos (Osma, Mallabia) y tampoco puede descartarse que la proliferación de topónimos como Ultzama / Untzama responda a alguna antigua moda toponímica. Sea como fuere, hay varios nombres en -ama que no se repiten en la Celtiberia, que son, por así decirlo, originales de Vasconia. Algunos de ellos serían únicos (Amiama, Arakama, Elama...) y otros no lo serían del todo, quiere decirse que puede haber dobletes en -isama / -isamo fuera de Vasconia (Berama / Beresmo, Zegama / Segisama...). Por lo tanto, no hay razones para pensar que todos los topónimos con la terminación -ama objeto del presente estudio sean importados; muchos de ellos pueden ser autóctonos. Todos esos datos abren la puerta a la hipótesis de la presencia de población de habla indoeuropea (céltica o no) en algunas zonas como el norte de Álava, Bizkaia, noroeste de Navarra y sobre todo sur de Gipuzkoa, pero no son suficientes para postular que el elemento indoeuropeo pre-latino era allí el originario y el vascónico el introducido, mucho menos en la totalidad del norte de la Vasconia ibérica.

6.2. A diferencia de las zonas circundantes a Vitoria y Pamplona (ciudades epicentro de varios sufijos de origen romano como -ain, -ana o -ano) en Bizkaia (-VKa), sur de Gipuzkoa (-ain, -ano, -ona) y norte de Álava (-ain, -ano, -ana) los topónimos con sufijos latinos y con la terminación -ama comparten territorio. Por el contrario, se observan sendas áreas toponímicas en torno a las ciudades de Pamplona y Vitoria con un claro vacío de muestras de -ama.

Al igual que las áreas toponímicas de los principales sufijos de origen latino empleados junto a bases antroponímicas para crear topónimos que indican posesión (-ain, -ana, -ano y -Vka), la topoglosa de -ama no refleja un dominio lingüístico uniforme en Vasconia. En la misma línea, los topónimos que combinan -ama e -i $(t) z$ se localizan en una zona muy concreta de Bizkaia.

Los nombres de lugar de Vasconia estudiados aquí podrían responder a dos estratos lingüísticos diferentes (siendo el segundo de ellos posiblemente de raigambre celtibérica), que indicarían una influencia indoeuropea relativamente dilatada, y no puntual. 
De igual forma, habiendo sido transmitidos a través de la lengua vascónica y habiendo evolucionado según sus reglas, los topónimos con la terminación -ama confirmarían que en la zona en que se sitúan había hablantes indígenas vascos en la época en que fueron creados o importados. En concreto, aunque no todos, varios de los cambios que se observan en los topónimos con -ama coinciden con los experimentados por los topónimos de origen latino que han evolucionado según las reglas de la lengua vasca (vid. $\$ 4$ 4).

Finalmente, entre las bases que se han combinado con -ama hay un elevado número de posibles raíces que tienen como núcleo la vocal media /e/ y que comienzan y terminan con una consonante que no se repite ${ }^{102}$. Como consonante inicial solo se observa /b/, /l/ o /z/ y como coda /g/, /d/ /l/, /r/, /z/ y /tz/, esto es, en el ataque faltan las oclusivas sordas, nasales, vibrantes y sibilantes ápico-alveolares y en posición final las oclusivas sordas, las nasales, la vibrante múltiple y las sibilantes ápico-alveolares. Ese paradigma sería, por un lado, ilustrativo de la forma canónica de la raíz en la lengua indoeuropea originaria pero, por otro lado, también lo sería en cierta parte del antiguo sistema consonántico de la lengua vasca (y su evolución), idioma en que fueron adoptados en su día.

6.3. La mayoría de los topónimos en -ama inventariados en Vasconia no se localizan en lugares con cualidades o características extraordinarias o muy destacables, por lo que es difícil relacionarlos con adjetivos superlativos. Muchas de las entidades geográficas denominadas por los nombres con - ama están relacionadas con la huella humana, con lugares de habitación o actividad económica.

Es probable que en topónimos como Arakama y Amiama la base sea un antropónimo (Aracus, Amius), de forma que, extrapolando a estos ejemplos el paradigma de los deantropónimos romanos, cabe preguntarse si en el momento de la creación de algunos topónimos en -ama no había también un elemento genérico o nombre común elidido (cfr. ager, fundus, terra, villa, vicus). Es más, puede pensarse que, además de Aracus y Amius, hay otras bases que se combinaron con -ama y con sufijos latinos empleados para crear topónimos que indican posesión, en vista de lo cual no parece que -ama tenga en todos los casos la misma relación con la base antecedente. En varios casos, a semejanza de algunos sufijos latinos (-[i][t]z, -ain...), puede pensarse que -ama se desligó, en cierto modo, del étimo, se hizo independiente del canon adjetivo + grado superlativo y se pudo añadir a bases antroponímicas indoeuropeas (para crear unos nombres que designen su hacienda o propiedad). Sin embargo, no se conocen testimonios de que la terminación -ama se haya combinado con bases antroponímicas vascónicas, lo que mostraría que no penetró o se integró en la lengua vasca con la misma intensidad que los sufijos latinos, esto es, que la influencia de la lengua de la que proviene sería mucho menor que la del latín. 
Con todo, la respuesta a la pregunta de si -ama expresa o indica en todos los casos lo mismo respecto a la base antecedente no parece afirmativa, puesto que, además de con raíces que responden al canon indoeuropeo $C e C$, se ha combinado con antropónimos de diversa índole.

6.4. En síntesis, de un examen de conjunto de los nombres de lugar con la terminación -ama, probablemente los materiales toponímicos más antiguos de Vasconia de los que se tiene constancia, se llega a resultados que confirmarían la influencia lingüística indoeuropea pre-latina (que no tiene por qué ser necesariamente de origen celtibérico) en el norte de Álava, Bizkaia, noroeste de Navarra y sur de Gipuzkoa.

El elemento indoeuropeo - ama se introdujo en Vasconia en un contexto lingüístico éuscaro y, además de posibles traslados toponímicos, no deben descartarse fenómenos de contacto relativamente continuado entre la lengua vascónica y lenguas indoeuropeas pre-latinas. Si se toma como indicador el elemento - ama, hay poca toponimia de origen indoeuropeo en Vasconia y, teniendo en cuenta que, tal y como afirma Mitxelena en su inestimable Sobre el pasado de la lengua vasca (p. 72.), la acción del acontecer histórico sobre una lengua solo es por mediación de otra lengua, puede concluirse que la huella de la cultura indoeuropea pre-latina en la toponimia de Vasconia no tiene la magnitud suficiente como para poner en tela de juicio la presencia del vasco antiguo al sur de los Pirineos antes de la romanización, especialmente en los territorios del norte de Álava, Bizkaia, noroeste de Navarra y sur de Gipuzkoa. Al hilo de lo anterior, cabe recordar que el número de representantes de -ama y el de los sufijos latinos añadidos a nombres de persona es muy dispar, ya que los primeros son mucho menos abundantes que los segundos.

Con todo, queda claro que aún hay varios aspectos de la terminación -ama por dilucidar, que -siendo fundamental- a la obra de Salaberri no se le ha sacado todavía todo el provecho y, sobre todo, que la toponimia, estudiada con criterios geográficos, puede aportar su grano de arena para aclarar, o al menos para plantear, ciertos problemas históricos, incluido el de la presencia de las lenguas indoeuropeas pre-latinas en el norte de la Vasconia ibérica. 


\section{BIBLIOGRAFÍA}

\subsection{Bibliografía}

Agud, M., 1973, «Áreas toponímicas en el País Vasco», Anuario del Seminario de Filología Vasca «Julio de Urquijo», 7, 37-55.

Ayerbe, M. R. y Elorza, J., 2008, Archivo Municipal de Zestoa (1338-1520), San Sebastián, Eusko Ikaskuntza, «Fuentes Documentales Medievales del País Vasco", 136.

Ayerbe, M. R. y San Miguel, A., 2013, Archivo Municipal de Ataun (1268-1519), San Sebastián, Eusko Ikaskuntza, «Fuentes Documentales Medievales del País Vasco", 146.

Albertos, M. L., 1966, La onomástica personal primitiva de Hispania: Tarraconense y Bética, Salamanca, CSIC-Instituto «Antonio de Nebrija».

- 1970, «Álava prerromana y romana. Estudio lingüístico», Estudios de Arqueología Alavesa, 4, 107-234.

- 1985, «La onomástica personal indígena del noroeste peninsular (astures y galaicos)", in De la Hoz, J. (ed.), Actas del III coloquio sobre lenguas y culturas paleohispánicas (Lisboa, 5-8 noviembre 1980), Salamanca, Ediciones Universidad de Salamanca, 255-308.

Aranberri, F., 2001, Ermua-Eitzaga leku-izenak: geure izanaren barrena, Bilbao, Real Academia de la Lengua Vasca, «Onomasticon Vasconiae», 22.

Arin, J., 1928, «Toponimia del pueblo de Ataun», Anuario Eusko de Folklore, 8, 55 153.

- 1956, «Notas acerca del pastoreo tradicional en Ataun», Anuario Eusko de Folklore, $15,77-124$.

AA. VV., 1996, Colección de documentos medievales de las villas guipuzcoanas: 1370-1397, San Sebastián, Diputación Foral de Gipuzkoa.

Barandiaran, I.; Madinabeitia, J. A. y Redondo, E., 1990, «Aproximación a la toponimia general de Encía, Iturrieta y Urbasa», in AA. VV., Los grupos bumanos en la prehistoria de Encía-Urbasa, San Sebastián, Eusko Ikaskuntza, 101-113.

BARKHAM, M., 1998, «Las pequeñas embarcaciones costeras vascas en el siglo XVI: notas de investigación y documentos de archivo sobre el "galeón", la "chalupa" y la "pinaza" ", Itsas memoria: revista de estudios marítimos del País Vasco, 2, 201-222.

Benveniste, É., 1935, Origines de la formation des noms en indo-européen, París, Maison-neuve.

BäHr, G., 1948, «Baskisch und Iberisch», Jakintza, 2, Bayona.

Caro Baroja, J., 1990 (1945), Materiales para una historia de la lengua vasca en su relación con la latina, San Sebastián, Txertoa. Publicado por primera vez en Salamanca en 1945 (Universidad de Salamanca).

Castillo, C., 2013, «Notas sobre onomástica de época romana relacionada con el territorio navarro", Cuadernos de Arqueología Universidad de Navarra, 21, 73-79. 
Crespo, P., 1998, Libro de la manifestación del maravedí de las aldeas de la ciudad de Daroca, Calamocha, Centro de Estudio del Jiloca.

De la Hoz, J. y Mitxelena, K., 1974, La inscripción celtibérica de Botorrita, Universidad de Salamanca, "Acta Salmanticensia. Filosofía y Letras», 80. Publicado nuevamente en 2011: J. A. Lakarra e I. Ruiz, (eds.), Luis Michelena. Obras Completas, Bilbao, Seminario de Filología Vasca «Julio de Urquijo», t. 3, 207-254.

Díez de Salazar Fernández, L. M., 1985, Colección diplomática del Concejo de Segura (Guipúzcoa) (1290-1500). Tomo I (1290-1400), San Sebastián, Eusko Ikaskuntza, «Fuentes Documentales Medievales del País Vasco», 06.

Diputación Foral de Gipuzkoa, 1857, Nomenclator de la provincia de Guipúzcoa, San Sebastián, Diputación Foral de Gipuzkoa. Abreviatura: NPG.

Elorza Guinea, J. C., 1967, «Ensayo topográfico de epigrafía romana alavesa», Estudios de Arqueología Alavesa, 2, 119-185.

Elorza Maiztegi, J., 2009, Documentación medieval del Archivo Municipal de Zumaia (1256-1520), San Sebastián, Eusko Ikaskuntza, «Fuentes Documentales Medievales del País Vasco", 139.

Enríquez, J., et. al., 1997, Foguera-Vecindario de las Villas de Vizcaya de 1511, San Sebastián, Eusko Ikaskuntza, «Fuentes Documentales Medievales del País Vasco», 78.

Esteban, M., 1990, El País Vasco atlántico en época romana, San Sebastián, Universidad de Deusto, "Cuadernos Universitarios (E.U.T.G.- Mundaiz)».

Fernández Palacios, F., 2002, Lengua e historia del Asón al Cadagua lépocas prerromana y romana), Madrid, Universidad Complutense de Madrid.

Fernández, M., Montecelo, L. y Herrero, V. J., 2007, Fuentes medievales del Archivo Municipal de Mutriku (1237-1520), San Sebastián, Eusko Ikaskuntza, «Fuentes Documentales Medievales del País Vasco», 130.

Galé, P.; Gorrotxategi, M. y Mugurutza, F., 2013, Aiarako toponimia nagusia / Toponimia mayor de Ayala, Bilbao, Real Academia de la Lengua Vasca, «Izenak», 3.

García Fernández, E., 1999, «La población de la villa guipuzcoana de Guetaria a fines de la Edad Media», En la España Medieval, 22, 317-353.

Goicolea, F. J., 1998, Archivo Municipal de Salvatierra-Agurain. Tomo II. (14011450), San Sebastián, Eusko Ikaskuntza, «Fuentes Documentales Medievales del País Vasco", 83.

- 2002, Archivo Municipal de Salvatierra-Agurain. Tomo III. (1451-1500), San Sebastián, Eusko Ikaskuntza, «Fuentes Documentales Medievales del País Vasco", 115.

Goñi Gaztambide, J., 1997, Colección diplomática de la catedral de Pamplona, Pamplona, Gobierno de Navarra.

Gorrochategui, J., 1984, Onomástica indígena de Aquitania, Bilbao, Universidad del País Vasco.

- 1991, «Descripción y posición lingüística del celtibérico», Seminario de Filología Vasca «Julio de Urquijo», anexo 14-1, 3-31.

- 1993, «La aportación de la lingüística a la reconstrucción del poblamiento del País Vasco", Ilunzar, 94, 113-125. 
— 2000, «La romanización del País Vasco: aspectos lingüísticos», Bitarte, 22, 87-105.

- 2009, «Las lenguas de los Pirineos en los tiempos antiguos, in J. Santos (ed.), Los tiempos antiguos en los territorios pirenaicos, Vitoria, Universidad del País Vasco, «Anejos de Veleia».

- 2015, «Arabako (eta inguruko) hizkuntzak antzinatean / Las lenguas de Álava (y alrededores) en la antigüedad", in Lenguas y hablantes de Álava en un mundo multilingüe, Vitoria, Diputación Foral de Álava, 5-20.

Gorrochategui, J. y de Bernardo, P., 2001-2002, «Los celtas y su religión a través de la epigrafía (Tercer Workshop F.E.R.C.A.N., Vitoria, septiembre de 2000)», Veleia, 18-19, 9-10.

Huarte, J. V., 1997, «Peremustae teonimoaren inguruan», FLV, 75, 167-172.

IRIGOIEN, A., 1972, «Formas de nombre de localidades vizcaínas», FLV, 11, 207-218.

— 1975, «La colegiata de Cenarruza y sus seles», in II Simposio sobre Historia del Señorío de Vizcaya, Bilbao, RSVAP-Junta de Cultura de Vizcaya, separata.

Jimeno Jurío, J. M. (dir.), 1992, Nafarroako toponimia eta mapagintza / Toponimia y cartografía de Navarra, Pamplona, Gobierno de Navarra. Cincuenta y nueve tomos, a partir del año 1992. Abreviatura: TCN.

Jordán, C., 1998, Introducción al celtibérico, Zaragoza, Universidad de Zaragoza, "Monografías de Filología Griega».

- 2004, Celtibérico, Zaragoza, Universidad de Zaragoza, «Monografías de Filología Griega».

Kerexeta, J., 1992, Fogueraciones de Bizkaia del siglo XviII, Bilbao, Labayru Institutua - Bilbao Bizkaia Kutxa.

Lacarra, J. M., 1957, Vasconia medieval. Historia y filología, San Sebastián, Diputación Foral de Gipuzkoa.

LAKARRA, J. A., 2011, «Erro monosilabikoaren teoria eta aitzineuskararen berreraiketa: zenbait alderdi eta ondorio", FLV, 113, 5-114.

LemA, J. A., et. al., 2002, El triunfo de las élites urbanas guipuzcoanas: nuevos textos para el estudio del gobierno de las villas y de la provincia (1412-1539), San Sebastián, Diputación Foral de Gipuzkoa.

López de Gereñu, G., 1989, Toponimia alavesa seguido de mortuorios y pueblos alaveses, Bilbao, Real Academia de la Lengua Vasca, «Onomasticon Vasconiae», 5 .

López Eire, A., 1971, «La teoría de Benveniste acerca de la raíz en indoeuropeo: precedentes y repercusiones», Estudios Clásicos, 64, 269-295.

Martínez Díez, G., 1975, Guipúzcoa en los albores de su historia (siglos X-XII), San Sebastián, Diputación Foral de Gipuzkoa.

Meyer-LübKe, W., 1925, «Sobre el conocimiento de los topónimos prerromanos de la península ibérica», in Homenaje ofrecido a Menéndez Pidal (I), Madrid, 63-84.

Mitxelena, K., 1953, Apellidos vascos, San Sebastián, Biblioteca Vascongada de los Amigos del País. Se ha empleado la cuarta de edición Txertoa (1989, San Sebastián). Abreviatura: $A V$.

- 1960, «Los dialectos indoeuropeos hispánicos», Zephyrus 11, 245-248. Publicado nuevamente en 2011: J. A. Lakarra e I. Ruiz (eds.), Luis Michelena. Obras Completas, Bilbao, Seminario de Filología Vasca «Julio de Urquijo», t. 3, 69-74. 
- 1985 (1961), Fonética Histórica Vasca, San Sebastián, Seminario de Filología Vasca «Julio de Urquijo» - Diputación Foral de Gipuzkoa, anexo 4, 3. a edición. Vio la luz por primera vez en 1961. Publicado nuevamente en 2011: J. A. Lakarra e I. Ruiz (eds.), Luis Michelena. Obras Completas, Bilbao, Seminario de Filología Vasca «Julio de Urquijo», t. 6. Abreviatura: FHV.

- 1964, Sobre el pasado de la lengua vasca, San Sebastián, Auñamendi.

— 1968, «Lat. s: el testimonio vasco», in A. Quilis, (ed.), XI Congreso Internacional de Lingüística y Filología Románicas. Actas. II, 473-489, Madrid, CSIC. Publicado nuevamente en 2011: J. A. Lakarra e I. Ruiz, (eds.), Luis Michelena. Obras Completas, Bilbao, Seminario de Filología Vasca «Julio de Urquijo", t. 1, 343-358.

— 1969, «Notas lingüísticas a "Colección diplomática de Irache”, FLV, 1, 1969, 1-59. Publicado nuevamente en 1987: Palabras y Textos, Leioa, Universidad del País Vasco, 87-140.

- 1972a, «Nota marginal sobre la huella latina en la lengua vasca», FLV, 4, 5-25. Publicado nuevamente en 2011: J. A. Lakarra e I. Ruiz, (eds.), Luis Michelena. Obras Completas, Bilbao, Seminario de Filología Vasca «Julio de Urquijo», t. 5, 277-302.

- 1972b, «Préstamos lingüísticos del latín al euskera», Estudios de Deusto, 20, 333-334. Publicado nuevamente en 2011: J. A. Lakarra e I. Ruiz (eds.), Luis Michelena. Obras Completas, Bilbao: Seminario de Filología Vasca «Julio de Urquijo», t. 5, 303-305.

- 1977, La lengua vasca, Durango, Leopoldo Zugaza. Publicado nuevamente en 2011: Lakarra, J. A. Lakarra e I. Ruiz (eds.), Luis Michelena. Obras Completas, Bilbao, Seminario de Filología Vasca «Julio de Urquijo», t. 4, 13-66.

- 1978, "Los textos hispánicos prerromanos en lengua indoeuropea», in Actas del V Congreso Español de Estudios Clásicos, Madrid, 433-448. Publicado nuevamente en 2011: J. A. Lakarra e I. Ruiz (eds.), Luis Michelena. Obras Completas, Bilbao, Seminario de Filología Vasca «Julio de Urquijo», t. 3, 17-36.

- 1982, «Sobre la lengua vasca en Álava durante la Edad Media», in J. L. Orella (ed.), Vitoria en la Edad Media. Actas del I Congreso de Estudios Históricos celebrado en esta ciudad del 21 al 26 de setiembre de 1981, en conmemoración del 800 aniversario de su fundación, Vitoria, RIEV 28, 299-306. Publicado nuevamente en 2011: J. A. Lakarra e I. Ruiz (eds.), Luis Michelena. Obras Completas, Bilbao, Seminario de Filología Vasca «Julio de Urquijo», t. 5, 403-418.

— 1986, «La lengua vasca», in J. Haritschelhar (dir.), Ser vasco, Bilbao, 225-265. Publicado nuevamente en 2011: J. A. Lakarra e I. Ruiz (eds.), Luis Michelena. Obras Completas, Bilbao, Seminario de Filología Vasca «Julio de Urquijo», t. 4, 79-124.

Murugarren, M., 1997, «Estudio de las comunidades pesqueras y documentación parroquial (The study of Fishing Communities and Parish Documentation)», Zainak, 15, 233-249.

Odriozola, L., 1998, «La construcción naval en Guipuzcoa», Itsas memoria: revista de estudios marítimos del País Vasco, 2, 93-146. 
Peñalver, X. y San José, S., 2003, Burdin Aroko herri harresituak Gipuzkoan, San Sebastián, Diputación Foral de Gipuzkoa, «Bertan», 20.

Perurena, P., 2010, Goizuetan bada gizon bat... Trabukoen kantako misterioak, Irun, Alberdania.

Pozuelo, F., 2010, Archivo Municipal de Salvatierra-Agurain. Tomo IV (1501-1521). Apéndice 1259-1469, San Sebastián, Eusko Ikaskuntza, «Fuentes Documentales Medievales del País Vasco», 141.

Prósper, B. M., 2004, «Varia palaeohispanica occidentalia», Palaeohispanica, 4, 169194.

— 2005, «Estudios sobre la fonética y la morfología de la lengua celtibérica», in F. Villar, y B. M. Prósper, Vascos, celtas e indoeuropeos. Genes y lenguas, Salamanca, Ediciones Universidad de Salamanca, "Acta salmanticensia, Estudios filológicos», 307, 157-366.

— 2010, «El topónimo hispano-celta Bletisama: una aproximación desde la lingüística», in I. Sastre Prats, y A. Beltrán Ortega (eds.), El bronce de El Picón (Pino del Oro): procesos de cambio en el occidente de Hispania, Valladolid, Junta de Castilla y León, 217-223.

Rabanal, M. A., 1994: «La Vía de la Plata en León, Zamora y Salamanca: de calzada romana a camino de peregrinación a Santiago», Studia Zamorensia, 1, 201-215.

Raymond, P., 1863, Dictionnaire topographique Béarn-Pays basque, Paris, Imprimerie Impériale.

Roldán, J. M., 1991, Colección diplomática del Archivo Municipal de Tolosa. Tomo I (1256-1407), San Sebastián, Eusko Ikaskuntza, «Fuentes Documentales Medievales del País Vasco», 35.

SAlaberri, P., 2000, «Acerca del sufijo toponímico -ain», FLV, 83, 113-137.

- 2003, Euskal Deiturategia: Patronimia, Bilbao, Udako Euskal Unibertsitatea.

- 2005, "Origen y significado de la toponimia de Navarra», in J. L. Ramírez Sádaba (ed.), La onomástica en Navarra y su relación con la de España. Actas de las Primeras Jornadas de Onomástica (Pamplona 2003), Pamplona, Universidad Pública de Navarra, 91-128.

- 2010, «Politics and Onomastics in the Basque Country. Historical and Current Situation», Onoma, 45, 217-235.

- 2011a, «De toponimia vasco-pirenaica: sobre el sufijo -otz, -oz(e)», Nouvelle revue d'onomastique, 53, 33-64.

- 2011b, «Sobre el sufijo occidental -ika y otras cuestiones de toponimia vasca», FLV $113,139-176$.

- 2012a, «Notas de toponimia alavesa: antrotopónimos en -a / -ana», in R. González de Viñaspre y R. Garay (eds.), Viaje a Íbita. Estudios históricos del Condado de Treviño, Vitoria, Ayuntamiento del Condado de Treviño, 209-228.

- 2012b, «Topónimos alaveses de base antroponímica terminados en -ain, -egi, -eta (-keta), -ika, -iku (-iko), -inu (-ina), -itu (-ita), -ón», FLV, 115, 323-357.

— 2013a, «Topónimos alaveses de base antroponímica acabados en -(i)ano», FLV, 116, 245-272.

- 2013b, «Topónimos alaveses de base antroponímica terminados en -iz, -ez y -ona / -oa», Lapurdum, 17, 201-220. 
- 2015, Araba / Álava. Los nombres de nuestros pueblos, Bilbao, Real Academia de la Lengua Vasca / Euskaltzaindia, «Izenak», 5.

San Martín, J., 2000, Eibar eta Elgetako toponomastika / Toponomástica de Eibar y Elgeta, Bilbao, Real Academia de la Lengua Vasca, "Onomasticon Vasconiae», 21.

Serrano, L., 1930, Cartulario de San Millán de la Cogolla, Madrid, Centro de Estudios Históricos.

Solin, H. y Salomies, O., 1994, Repertorium nominum gentilium et cognominum latinorum, Hildesheim - Zürich - New York, Olms - Weidmann, 2. ${ }^{\text {a ed. }}$

Untermann, J., 2001, «La toponimia antigua como fuente de las lenguas hispanoceltas», Palaeohispanica, 1, 187-218.

Velaza, J., 2009, «Epigrafía y literacy paleohispánica en territorio vascón: notas para un balance provisional», in F. Beltrán Lloris et al., (eds.), Acta Palaeohispanica X. Actas del IX Coloquio sobre lenguas y culturas paleohispánicas, Zaragoza, 611-622.

VILlar, F., 1995, Estudios de celtibérico y de toponimia prerromana, Salamanca, Universidad de Salamanca.

— 2005a, «Topónimos y estratigrafía de las lenguas», in F. Villar, y B. M. Prósper, Vascos, celtas e indoeuropeos. Genes y lenguas, Salamanca, Ediciones Universidad de Salamanca, «Acta Salmanticensia, Estudios filológicos», 307, 13-156.

- 2005b, «Indoeuropeos y euskaldunes en el País Vasco y Navarra. Genes, lenguas y topónimos», in F. Villar y B. M. Prósper, Vascos, celtas e indoeuropeos. Genes y lenguas, Salamanca, Ediciones Universidad de Salamanca, «Acta Salmanticensia, Estudios filológicos», 307, 367-514.

ZALDUA, L. M., 2015, «Saroi entitate geografikoaren banaketa, esanahia eta jatorria toponimiaren argitan», FLV, 119, 175-221.

\subsection{Archivos}

Archivo General de Navarra

1565, signatura: F146/160280. Abreviatura: AGN1.

Archivo Histórico de Álava (Abreviatura: AHA)

1729, Copia simple del litigio entre María Manuela de Sarove Barrena y Antonio de Ayestarán, sobre la posesión del Mayorazgo Martínez de Ayestarán, y su sentencia. Signatura: ATHA-DAH-FAVE-021-016-01 (ff. 1-14).

Archivo Histórico Diocesano de Gipuzkoa

1634, signatura: 1141/001-06. Abreviatura: AHDG1.

1606, signatura: 3224/001-01. Abreviatura: AHDG2.

1891, signatura: 2955/002-01. Abreviatura: AHDG3.

\section{Archivo Histórico de Zegama}

1815, signatura: libro 174, expediente 2. Abreviatura: AHZ1.

1841, signatura: libro 226, expediente 2. Abreviatura: $A H Z 2$.

1945, signatura: libro 171, expediente 2. Abreviatura: AHZ3. 


\section{Archivo de la Real Chancillería de Valladolid}

1523, signatura: Registro de Reales Ejecutorias. C 363/35. Abreviatura: ARCHV1. 1575, signatura: Pleitos Civiles. Alonso Rodríguez. Fenecidos. C 407/1. Abreviatura: ARCHV2.

1595, signatura: Pleitos Civiles. Taboada. Fenecidos. C 731/10, L 139. Abreviatura: ARCHV3.

Archivo de la Casa Zabala (Abreviatura: ACZ)

1829, signatura: 113.5 .

\subsection{Bases de datos y ediciones en línea}

Diputación Foral de Álava

Infraestructura de Datos Espaciales de Araba / Álava. Nomenclátor de Araba / Álava. $<$ http://www.ide-alava.com/dfa/index>. Abreviatura: IDEA.

\section{Diputación Foral de Bizkaia}

Base de datos con topónimos y nombres de lugar normalizados por la Real Academia de la Lengua Vasca.

<http://www.bizkaia.eus/home2/Temas/DetalleTema.asp?Tem_Codigo=358>.

\section{Gobierno De Navarra}

Sistema de Información Territorial de Navarra (SITNA).

$<$ http://sitna.navarra.es/geoportal/?lang=>.

\section{Gobierno VAsco}

Infraestructura de Datos Espaciales de Euskadi (GeoEuskadi).

<http://www.geo.euskadi.eus/s69-15375/es/>.

Institut GÉographique National

Cartographie Institut Géographique National.

<www.geoportail.fr.> <geoportail.gouv.fr/accueil>. Abreviatura: IGNF.

\section{Instituto Geográfico Nacional}

Nomenclator Geográfico Básico de España.

$<$ http://centrodedescargas.cnig.es/CentroDescargas/equipamiento/NGBEv2013.zip>. Abreviatura: NGBE.

\section{Instituto Nacional de Estadística}

Aplicativo apellidos. INEbase / Demografía y población / Frecuencias de apellidos.

$<$ http://www.ine.es/apellidos/inicio.do>. Abreviatura: INE.

\section{Real Academia de la Lengua Vasca}

Base de datos onomásticos eusquéricos.

$<$ http://www.euskaltzaindia.eus/index.php?option=com_content $\& v i e w=\operatorname{article} \& i d=41$ 57\&Itemid=698\&lang=es\}>. Abreviatura: EODA. 
Universidad Complutense de Madrid

Hesperia-Banco de Datos de Lenguas Paleohispánicas. $<$ http://hesperia.ucm.es>. Abreviatura: Hesperia-BDLP.

Universidad del País Vasco

Edición electrónica del Becerro Galicano de San Millán de la Cogolla $<$ http://www.ehu.eus/galicano/>.

Gonzalo Muñoz y su mujer donan a San Millán su parte del monasterio de San Andrés de Bolivar y de varias posesiones en La Rioja, al tiempo que Diego González, Urraca y Álvaro González hacen lo mismo con su parte del mencionado cenobio. <http://www.ehu.eus/galicano/id 478>. Abreviatura: UPV-Galicano.

\section{RESUMEN}

Sobre el elemento indoeuropeo pre-latino en la toponimia de Vasconia: los nombres de lugar terminados en -ama

Este trabajo, en primer lugar, amplía el inventario de nombres de lugar terminados en -ama estudiados hasta la fecha con nuevas muestras. Una vez clasificados, teniendo presente las aportaciones de otros autores, se procura aclarar el posible origen de los topónimos que portan la terminación en cuestión, para, finalmente, analizar su distribución territorial e intentar extraer algunas conclusiones sobre el elemento indoeuropeo pre-latino en la toponimia de Vasconia.

Palabras clave: -ama; indoeuropeo; pre-latino; toponimia; onomástica; lengua vasca; historia; Vasconia.

\section{LABURPENA}

Latinaren aurreko osagai indoeuroparra Euskal Herriko toponimian: -ama bukaera duten toki-izenak

Lan honek, lehenik eta behin, gaurdaino ikertutako -ama bukaera duten toki-izenen zerrenda zabaltzen du ale berriekin. Sailkatu ondoren, beste ikertzaile batzuen lanak aintzat hartuz, azterturiko amaiera daramaten toponimoen balizko jatorria argitzeko ahalegina egiten da, azkenik, lurraldean nola banatuta dauden aztertu eta Euskal Herriko toponimiako latinaren aurreko elementu indoeuroparraz ondorio batzuk ateratzen saiatzeko.

Gako hitzak: -ama; indoeuropar; latinaren aurreko; toponimia; onomastika; euskara; historia; Euskal Herria. 


\section{ABSTRACT}

Concerning the Indo-European Pre-Latin element in the toponymy of Vasconia: place names ending in -ama

This paper broadens, first of all, the stock of place names ending in -ama by means of providing new samples. Once these have been classified, an attempt is undertaken to elucidate the potential origin of those toponyms bearing said ending, always bearing in mind contributions to the field made by other authors. To conclude, the territorial distribution of those place names is analyzed and an effort is made to draw a number of conclusions regarding the pre-Latin Indo-European element in the toponymy of Vasconia.

Keywords: -ama; Indo-European; pre-Latin; toponymy; onomastics; Basque; History; Vasconia. 
0000 